\title{
The Molecular Roles and Clinical Implications of Non-Coding RNAs in Gastric Cancer
}

\author{
Yanping Yue ${ }^{1 \dagger}$, Xinrong Lin $^{2 \dagger}$, Xinyue Qiu ${ }^{1}$, Lei Yang ${ }^{1 *}$ and Rui Wang ${ }^{2 *}$ \\ ${ }^{1}$ Department of Medical Oncology, Affiliated Cancer Hospital, Nantong University, Nantong, China, ${ }^{2}$ Department of Medical \\ Oncology, Affiliated Jinling Hospital, Medical School of Nanjing University, Nanjing, China
}

OPEN ACCESS

Edited by:

Peixin Dong,

Hokkaido University, Japan

Reviewed by:

Milad Ashrafizadeh,

Sabancı University, Turkey

Miao Liu,

Harvard Medical School,

United States

Kongning $\mathrm{Li}$,

Hainan Medical University, China

*Correspondence: Lei Yang

leiyang.53@163.com

Rui Wang

wangrui218@163.com

${ }^{t}$ These authors have contributed equally to this work

Specialty section:

This article was submitted to Molecular and Cellular Oncology,

a section of the journal

Frontiers in Cell and Developmental

Biology

Received: 27 October 2021 Accepted: 29 November 2021

Published: 13 December 2021

Citation:

Yue Y, Lin X, Qiu X, Yang L and Wang R (2021) The Molecular Roles and Clinical Implications of Non-Coding RNAs in Gastric Cancer. Front. Cell Dev. Biol. 9:802745. doi: 10.3389/fcell.2021.802745
Gastric cancer (GC) is one of the most common malignancies in the world. It is also the fifth most common cancer in China. In recent years, a large number of studies have proved that non-coding RNAs (ncRNAs) can regulate cell proliferation, invasion, metastasis, apoptosis, and angiogenesis. NcRNAs also influence the therapeutic resistance of gastric cancer. NcRNAs mainly consist of miRNAs, IncRNAs and circRNAs. In this paper, we summarized ncRNAs as biomarkers and therapeutic targets for gastric cancer, and also reviewed their role in clinical trials and diagnosis. We sum up different ncRNAs and related moleculars and signaling pathway in gastric cancer, like Bcl-2, PTEN, Wnt signaling. In addition, the potential clinical application of ncRNAs in overcoming chemotherapy and radiotherapy resistance in GC in the future were also focused on.

Keywords: gastric cancer, non-coding RNA, therapy resistance, microRNA, IncRNA

\section{INTRODUCTION}

Gastric cancer (GC) is the fifth most common type of cancer and the third most common cause of cancer-related deaths worldwide after lung and colorectal cancer (Bray et al., 2018). In 2018, the global age-standardized incidence and mortality rates for GC were 11.1 and 8.2 per 100,000 persons, respectively (Thrift and El-Serag, 2020). The Global Burden of Disease Study (GBD) 2017 showed that the global age-standardized incidence decreased by $28.0 \%$ in 2017 compared with that in 1990, and the age-standardized mortality decreased by $48.7 \%$ (ollaborators, 2020). The uniform declines in incidence have been observed in many parts of the world for decades, including China (Luo et al., 2017). Early detection of gastric cancer is considered to have contributed to favorable survival (Sekiguchi et al., 2021). In 2004, an early detection and treatment program was initiated in China with special funds from the Ministry of Health (Zheng et al., 2015). Therefore, one of the main reasons for the improvement of gastric cancer is the popularity of endoscopic screening (Zhang et al., 2018a). Endoscopic resection is the preferred treatment for early GC, whereas traditional surgery, including D2 lymphadenectomy, consisting of lymph node stations in the perigastric mesentery and along the celiac arterial branches, is the main treatment for operable GC (Hiki et al., 2013; PimentelNunes et al., 2015). The first line of treatment for patients with advanced GC consists of sequential chemotherapy with platinum and fluoropyrimidine (Smyth et al., 2016). Targeted therapies currently approved to treat GC include trastuzumab as first line therapy for HER2-positive patients, ramucirumab as an anti-angiogenic agent for second line treatment, and nivolumab or pembrolizumab as an anti-PD-1 agent for third line treatment (Group et al., 2010; Fuchs et al., 2014; Kang et al., 2017). Some patients, however, have multiple drug resistance (MDR) to these agents, leading to a poor prognosis. Understanding the mechanisms underlying resistance to these drugs is needed to develop new methods for accurate early detection and effective treatment of GC. 


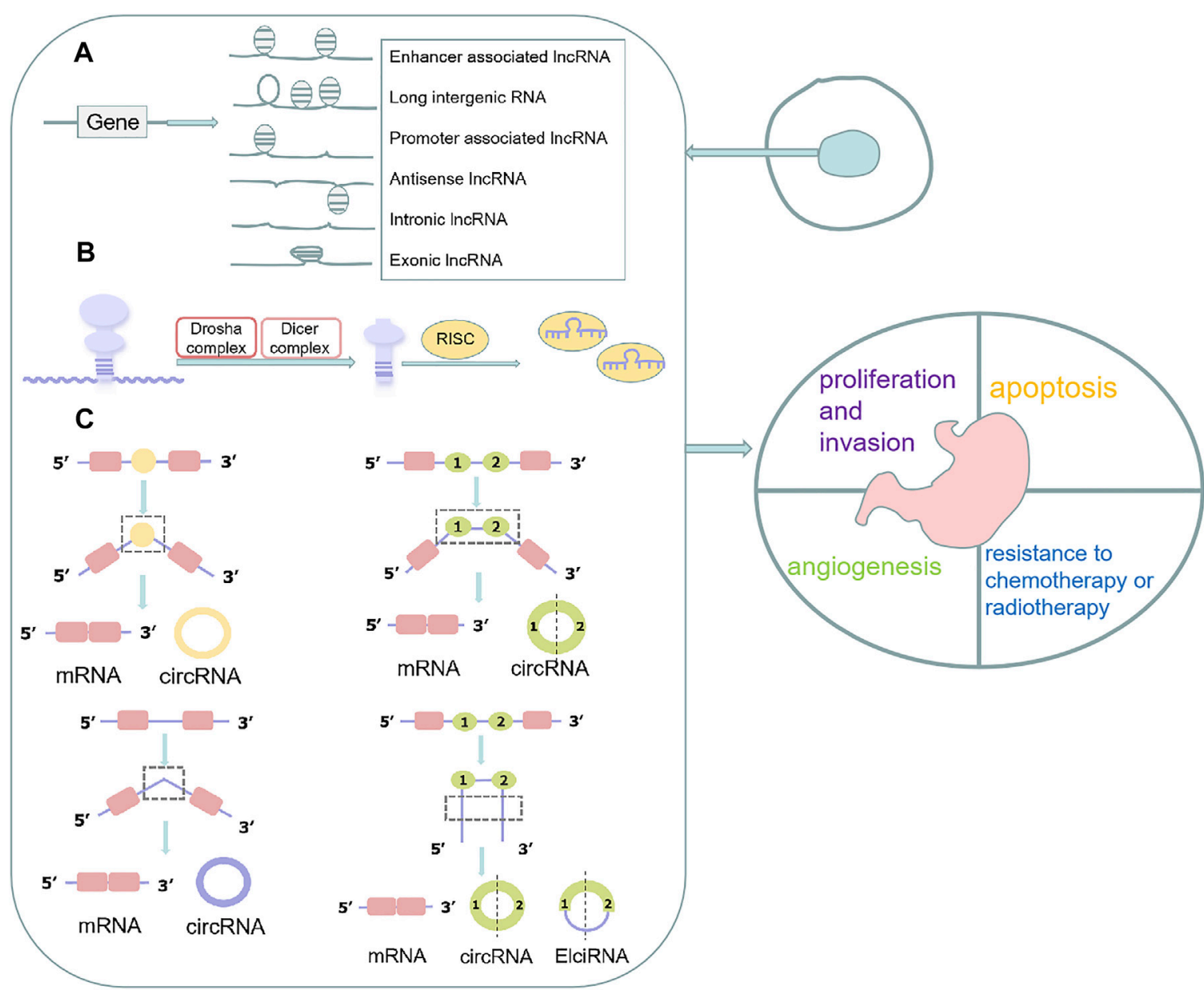

FIGURE 1 | Function, biogenesis and localization of ncRNAs in cells. (A) IncRNAs are classified into various categories, including promoter-related IncRNAs, enhancer-related IncRNAs, intronic and exonic IncRNAs, antisense IncRNAs, and long intergenic IncRNAs; (B) The pre-miRNAs are loaded into the RNA-induced silencing complex (RISC) where the mature single-stranded miRNA binds to complementary mRNA targets after processed by Drosha complex and Dicer complex; (C) CircRNAs are classified into different types, including intron circRNAs, exon circRNAs, and extron-intron circRNAs.

Non-coding RNAs (ncRNAs) are unique transcripts that do not encode proteins (Esteller and Pandolfi, 2017). According to the length and shape, ncRNAs can be subdivided into the following types: tiny/short ncRNAs, long ncRNAs (lncRNAs) and circular RNA (circRNAs). There are various small ncRNAs, such as microRNAs (miRNAs), PIWI-interacting RNAs (piRNAs), small nucleolar RNAs (snoRNAs) and small nuclear RNAs (snRNAs) (Wei et al., 2019). The most widely studied class of ncRNAs are miRNAs, which are small ncRNAs of $\sim 22$ nucleotides (nt) that, in animals, mediate post-transcriptional gene silencing by controlling the translation of mRNA into proteins (He and Hannon, 2004). LncRNAs are a heterogeneous group of non-coding transcripts more than $200 \mathrm{nt}$ long that are involved in many biological processes (Esteller, 2011). PiRNAs are ncRNAs of 24-30 nt in length, are Dicer-independent and bind the PIWI subfamily of Argonaute family proteins that are involved in maintaining genome stability in germline cells (Aravin et al., 2007).
SnoRNAs are intermediate-sized ncRNAs (60-300 bp). They are components of small nucleolar ribonucleoproteins (snoRNPs), which are complexes that are responsible for sequence-specific 2'-O-methylation and pseudouridylation of ribosomal RNA (rRNA) (Ni et al., 1997). Several of these ncRNAs have been found to act as key regulators of various cell functions in GC, including cell proliferation, apoptosis, the cell cycle, and cellular metabolism (ChunZhi et al., 2010; Liu et al., 2019a; Zhang et al., 2019a). Moreover, some ncRNAs were reported closely related to the development of chemoresistance in GCs (Liu et al., 2019a; Xi et al., 2019) (Figure 1).

This review systematically summarizes current knowledge about the mechanisms by which ncRNAs regulate cell proliferation, invasion, and apoptosis, as well as their impact on drug resistance. Elucidation of these mechanisms may provide insight into the future use of ncRNAs as hypothetical biomarkers and/or therapeutic targets of GC. 
TABLE 1 | NcRNAs and oncogenes and suppressor genes in gastric cancer behavior.

\begin{tabular}{|c|c|c|c|c|}
\hline NcRNA & $\begin{array}{l}\text { Targeted } \\
\text { genes }\end{array}$ & $\begin{array}{l}\text { Genetic } \\
\text { properties }\end{array}$ & References & behavior \\
\hline $\begin{array}{l}\text { IncRNA HOXA11-AS;IncRNA MNX1-AS1; IncRNA } \\
\text { FOXP4-AS1 }\end{array}$ & $\mathrm{EZH} 2$ & oncogene & Liu et al. (2017); Shuai et al. (2020); Chen et al. (2019a) & proliferation \\
\hline $\begin{array}{l}\text { IncRNA LINC00673;IncRNA FOXD2-AS1; IncRNA } \\
\text { UCA1 }\end{array}$ & & & Huang et al. (2017a); Xu et al. (2018); Wang et al. (2017) & \\
\hline IncRNA SNHG6;IncRNA SPRY4-IT1;IncRNA & & & Li et al. (2018a); Zhou et al. (2017a); Han et al. (2020) & \\
\hline PART1 & & & & \\
\hline IncRNA AFAP1-AS1;IncRNA SNHG17;IncRNA & & & Yuan et al. (2020); Zhang et al. (2019b); Qi et al. (2017a) & \\
\hline AGAP2-AS1 & & & & \\
\hline IncRNA OIP5-AS1;IncRNA CASC15;IncRNA & & & Bai and Li (2020); Wu et al. (2018a); Song et al. (2019) & \\
\hline HOTAIR & & & & \\
\hline miR-101;miR-31;miR-26b & & & Carvalho et al. (2012); Sun et al. (2019); Rossi et al. (2019) & \\
\hline miR-370;miR-138-5p;miR-204-5p;miR-146a & EGFR & oncogene & Ning et al. (2017); Wang et al. (2018a); Kogo et al. (2011) & \\
\hline $\mathrm{miR}-873$ & STRA6 & oncogene & Lin et al. (2019) & \\
\hline $\operatorname{miR}-133 b$ & FSCN1 & oncogene & Guo et al. (2014) & \\
\hline $\mathrm{miR}-511$ & TRIM24 & oncogene & Fang et al. (2017) & \\
\hline miR-216a;miR-18a & RUNX1 & suppressor gene & $\begin{array}{l}\text { Wu et al. (2018b) } \\
\text { Qi et al. (2020) }\end{array}$ & \\
\hline miR-5683 & PDK4 & oncogene & Miao et al. (2020) & \\
\hline miR-885 & YPEL1 & suppressor gene & Li et al. (2019a) & \\
\hline miR-122 & LYN & oncogene & Meng et al. (2020) & \\
\hline miR-665 & PPP2R2A & oncogene & Zhang et al. (2020a) & \\
\hline LINC00152;miR-383;miR-1915-3p;miR-24 & $\mathrm{Bcl}-2$ & oncogene & $\begin{array}{l}\text { Tao et al. (2021); Cui et al. (2019); Mao et al. (2019); Zhang } \\
\text { et al. (2016a) }\end{array}$ & apoptosis \\
\hline miR-23a/b;miR-499-5p;miR-183; miR-93 & PDCD4 & suppressor gene & $\begin{array}{l}\text { Hu et al. (2017); Yang et al. (2020); Li et al. (2016); Liang et al. } \\
\text { (2016) }\end{array}$ & \\
\hline miR-200a;IncRNA XIAP-AS1 & TRAIL & suppressor gene & Guo et al. (2018); Cai et al. (2017) & \\
\hline LncRNA PVT1;miR-125a;miR-1 & VEGF & oncogene & $\begin{array}{l}\text { Dai et al. (2015); Xie et al. (2018); Zhao et al. (2018); Xie et al. } \\
\text { (2020a) }\end{array}$ & angiogenesis \\
\hline X26nt;IncRNA MALAT1 & VE-cadherin & oncogene & Chen et al. (2021a); Li et al. (2017a) & \\
\hline
\end{tabular}

\section{MECHANISMS OF NCRNAS THAT REGULATE GASTRIC CANCER BEHAVIOR}

Multiple ncRNAs dysregulate the behavior of GC by posttranscriptionally binding to the $3^{\prime}$ UTR of downstream gene mRNAs, including mRNAs encoded by various oncogenes, such as EZH2, EGFR, STRA6, FSCN1, TRIM24, PDK4, LYN, and PPP2R2A, and suppressor genes, such as PTEN, RUNX1, and YPEL1 (Table 1) (Markopoulos et al., 2017). In addition, complex interactions among internal members play crucial roles in proliferation, apoptosis, angiogenesis, and other behaviors by affecting classic signaling pathways.

\subsection{Proliferation and Invasion of ncRNAs}

$E Z H 2$, which plays a central role in all aspects of GC pathogenesis, is more highly expressed in GC tissues than in non-tumor epithelium, with increased expression associated with more aggressive biological behavior and poor prognosis of GC (Gan et al., 2018). The lncRNAs HOXA11-AS, MNX1-AS1, and FOXP4-AS1, and the microRNAs -101, -31, and -26b, all have an impact on the progression of GC by altering the level of expression of EZH2 (Carvalho et al., 2012; Huang et al., 2017a; Qi et al., 2017a; Zhou et al., 2017a; Liu et al., 2017; Wang et al., 2017; Li et al., 2018a; Wu et al., 2018a; Xu et al., 2018; Chen et al., 2019a; Zhang et al., 2019b; Rossi et al., 2019; Song et al., 2019; Sun et al., 2019; Bai and Li, 2020; Han et al., 2020; Shuai et al., 2020; Yuan et al., 2020). Epidermal growth factor receptor (EGFR) is an oncogenic transmembrane receptor that is overexpressed in many cancers, including GC (Zhen et al., 2014). MiRs-370 (Ning et al., 2017), -138-5p, and -204-5p (Wang et al., 2018a), and -146a (Kogo et al., 2011) target EGFR, thereby altering the migration and proliferation of GC cells. MiR-873, which down-regulates STRA6 mRNA in GC, plays a suppressor role (Lin et al., 2019). MiR-133b directly targets and inhibits FSCN1, which acts as an oncogene in GC cells, whereas miR-511 inhibits the tumor suppressor gene TRIM24 in GC (Guo et al., 2014; Fang et al., 2017). MiR-216a and miR-18a directly target and downregulate RUNX1 (Wu et al., 2018b; Qi et al., 2020); and miR-5683 promotes glycolysis and progression by up-regulating PDK4 expression (Miao et al., 2020). In addition, miR-885, which targets YPEL1, enhances GC cell proliferation, colony formation, and invasion; and miR-122 and miR-665 inhibit proliferation, invasion, and EMT by reducing the expression of $L Y N$ and PPP2R2A, respectively, in GC (Li et al., 2019a; Zhang et al., 2020a; Meng et al., 2020).

In addition, many other lncRNAs and circRNAs act as competitive endogenous RNAs (ceRNAs) of miRNAs, regulating the expression of oncogenes or tumor suppressor genes in GC. For example, the lncRNA LINC0130, which inhibits miR-101-3p activity, enhances the expression of $E Z H 2$, thereby promoting GC progression (Cao et al., 2019). The lncRNA MT1JP has been shown to act as a ceRNA for miR92a-3p, up-regulating the expression of FBXW7 and reducing GC cell proliferation (Zhang et al., 2018b). The lncRNA 
LINC00240 promotes GC through the LINC00240/miR-124-3p/ DNMT3B axis as an oncogene (Li et al., 2020a). By binding to and neutralizing miR-286-5p, CircPSMC3 enhances the expression of PTEN (Rong et al., 2019). CircGRAMD1B plays a negative role in GC progression by affecting the miR-130A-3P-PTEN/P21 axis (Dai et al., 2019). CircFAT1 binds to and neutralizes miR-548g, increasing the expression of the tumor suppressor gene RUNX1 in GC cells (Fang et al., 2019). Hsa-circ-0017639 promotes GC proliferation and metastasis by binding to and neutralizing miR-224-5p, thereby up-regulating USP3 expression (Li et al., 2020b).

NcRNAs are involved in many pathways, including the PTEN/ $\mathrm{PI} 3 \mathrm{~K} / \mathrm{AKT} / \mathrm{mTOR}$, Hippo, and $\mathrm{Wnt} / \beta$-catenin signaling pathways, adding a new dimension to the understanding of GC progression. The LncRNA BX357664, which acts as a ceRNA of miR-183-3p to target PTEN, affects the PI3K/AKT/ mTOR pathway and inhibits GC proliferation and metastasis (Liang et al., 2021). LncRNA HORAIRM1 acts as a ceRNA of miR-17-5p to up-regulate the expression of PTEN and mediate the PI3K/AKT pathway (Lu et al., 2019). By binding to and neutralizing miR-149-5p, circNRIP1 affects the level of expression of the AKT/mTOR axis and acts as a tumor promoter in GC (Zhang et al., 2019c). Overexpression of the circRNA ciRS-7 inhibits the tumor suppressor effect of miR-7 through the PTEN/PI3K/AKT signaling pathway (Pan et al., 2018). The lncRNA HCG18, which inhibits the expression of miR-141-3p; the lncRNA LINC00649, which targets miR-16-5p; and circLARP4, which adsorbs miR-424 are all directly implicated in the proliferation and invasion of GC cells by influencing the Hippo signaling pathway (Zhang et al., 2017a; Liu et al., 2020). The lncRNAs LINC01133, OIP5-AS1, and LINC01355, which bind to and neutralize miR-106a-3p, miR367-3p, and miR-431-5p, respectively, all activate the Wnt/ $\beta$-catenin signaling pathway and induce cell proliferation (Yang et al., 2018a; Tao et al., 2020; Piao et al., 2021).

\subsection{Apoptosis of ncRNAs}

At present, the known apoptosis-related genes in GC include those encoding the anti-apoptosis-related factors genes B-cell lymphoma-2 (Bcl-2), programmed cell death 4 (PDCD4), and tumor necrosis factor-alpha-related apoptosis-inducing ligand (TRAIL) (Carthy et al., 2003; Wu et al., 2004; Wang et al., 2010; Zhu et al., 2016; Lim et al., 2017). In addition, gastric cancer cells may undergo apoptosis through the MAPK/ERK, $\mathrm{PI} 3 \mathrm{~K} / \mathrm{Akt} / \mathrm{mTOR}, \mathrm{Wnt} / \beta$-catenin and other signaling pathways (Fattahi et al., 2020; Su et al., 2020). Many studies have found that ncRNAs related to these genes and signaling pathways play important roles in the GC cell apoptosis.

The anti-apoptotic protein Bcl-2 has been shown to play an important role in GC. MiR-383 and miR-1915-3p have been shown to reduce Bcl-2 expression in GC, whereas LINC00152 has the opposite effect (Cui et al., 2019; Mao et al., 2019; Tao et al., 2021). The expression of BCL2L11, a pro-apoptotic member of the Bcl-2 family, is reduced by miR-24, thereby inhibiting apoptosis (Zhang et al., 2016a). The roles of tumor suppressor PDCD4 in GC mainly include promoting cell apoptosis. PDCD4 may be a key downstream protein in the development of GC
(Zhao et al., 2020). MiR-23a/b, miR-499-5p, miR-183, miR-93 all target and negatively regulate PDCD4 to promote GC development (Li et al., 2016; Liang et al., 2016; Hu et al., 2017; Yang et al., 2020). TRAIL is a protein that promotes apoptosis in cancer cells by inducing the formation of the death-inducing signal complex (DISC). Over-expression of miR-200a and knockdown of the IncRNA XIAP-AS1 enhance TRAILinduced apoptosis in GC cells (Cai et al., 2017; Guo et al., 2018).

MiR-206 targets and suppresses MAPK3 mRNA, whereas miR-135b activates MAPK/ERK signaling, thereby affecting GC cell apoptosis (Chen et al., 2019b; Zhou and Chen, 2019). The lncRNA BCAR4 facilitates MAPK/ERK signaling, whereas the IncRNA LINC00858 reduces the methylation of the WNK2 gene promoter and its downstream MAPK signaling pathway (Zhou et al., 2020; Du et al., 2021). As such, ncRNAs function as master regulators of apoptosis in GC by controlling two other signaling pathways, the $\mathrm{PI} 3 \mathrm{~K} / \mathrm{Akt} / \mathrm{mTOR}$ and $\mathrm{Wnt} / \beta$-catenin pathways. Some of these regulatory molecules, including miR495 (Wang et al., 2018b), miR-193b (Tian et al., 2020a), miR-1395p (Zhang et al., 2020b), lncRNA SLC25A5-AS1 (Li et al., 2019b), and miR-195-5p (Zhao and $\mathrm{Wu}, 2019$ ), inactivate both pathways; whereas others, including miR-194 (Peng et al., 2018), miR-3243p (Sun et al., 2018), and LINC00355 (Luan et al., 2020), activate both pathways to inhibit apoptosis of GC cells.

\subsection{Angiogenesis of ncRNAs}

Tumor expansion depends on angiogenesis, as blood vessels provide oxygen and nutrients to tumors (Carmeliet and Jain, 2011). Angiogenesis is therefore essential for tumor occurrence, progression, invasion, migration, and metastasis (Hanahan and Weinberg, 2000). Tumors and stromal cells secrete abnormal levels of growth factors that cause tumor vascular dysplasia, including vascular disorders, immaturity, and permeability (Viallard and Larrivée, 2017). The important role of angiogenesis in gastric cancer and other tumors has been extensively studied. Inhibition of the angiogenesis signaling pathway will help prevent tumor growth and prolong the survival time of cancer patients. For gastric cancer, the REGARD trial, RAINBOW trial, and several ongoing RCTs have shown that ramucirumab that targeting VEGF signals help GC patients to achieve better survival (Li et al., 2021).

Continuous expression of vascular endothelial growth factor (VEGF) can stimulate angiogenesis (Maeda et al., 1996). Low expression of miR-125a maintains the secretion of VEGF-A in GC, thereby modulating tumor angiogenesis (Dai et al., 2015). Overexpression of miR-1 inhibits the growth of blood vessels by reducing the expression of VEGF-A and endothelin 1 (EDN1) (Xie et al., 2018). The lncRNA PVT1 plays an important role in GC angiogenesis by activating the STAT3/VEGFA axis (Zhao et al., 2018). The adsorption of circSHKBP1 on exosomes by miR582-3p enhances the stability of VEGF mRNA (Xie et al., 2020a).

Vascular endothelial cadherin (VE-cadherin) has been shown to enhance vascular permeability, angiogenesis and tumor growth (Viallard and Larrivée, 2017). The exosomal 26-nt-long ncRNA (X26 nt) secreted by GCs can target VE-cadherin to increase angiogenesis and vascular permeability (Chen et al., 2021a). The long-chain non-coding RNA MALAT1 was shown to enhance the 


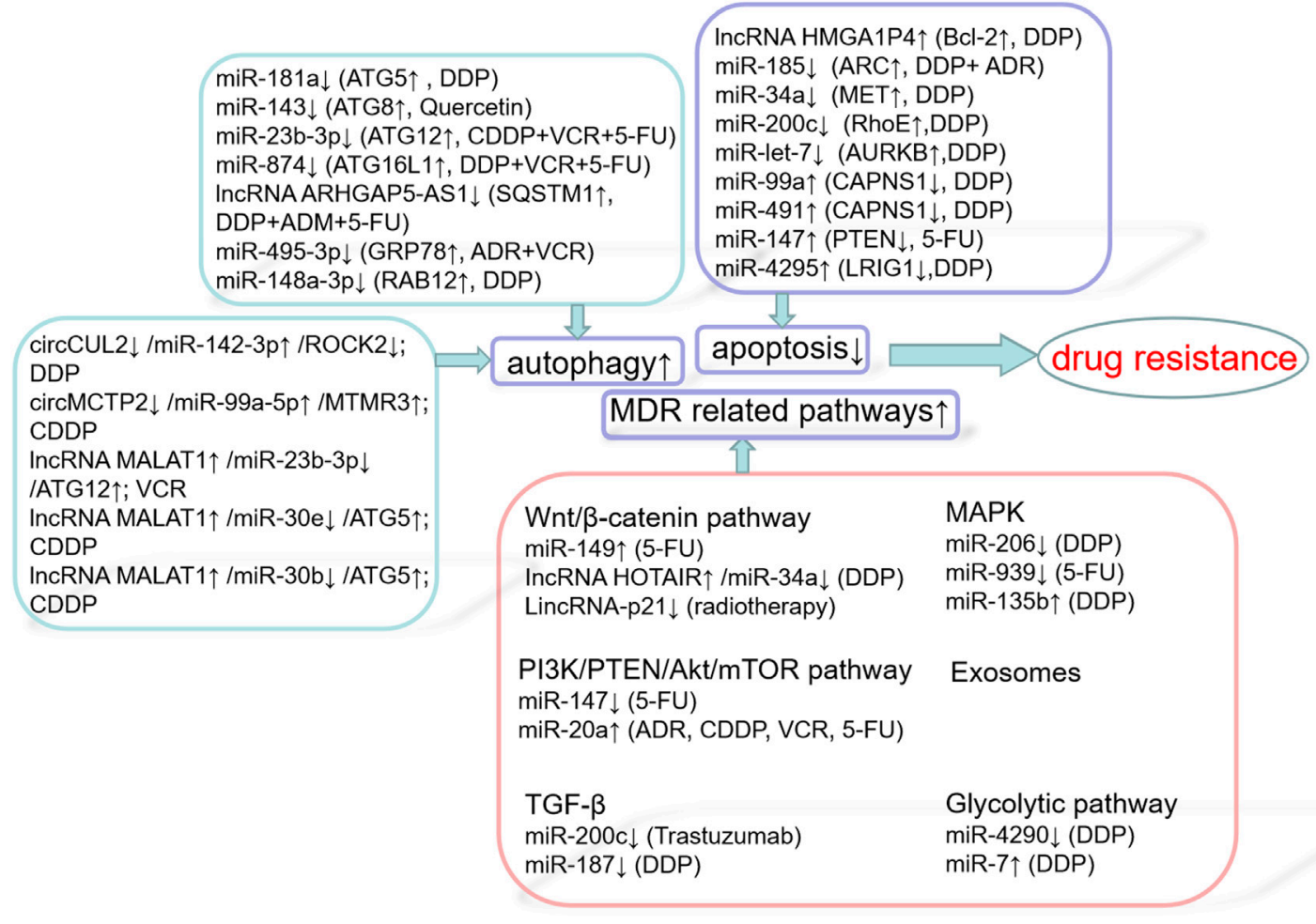

FIGURE 2 | Drug resistance mechanisms of ncRNAs.

expression of classic markers such as VE-cadherin and components of related signaling pathways to promote blood vessel growth and angiogenesis (Li et al., 2017a).

Exosomes are nano-scale membrane vesicles containing proteins, lipids, mRNA, and miRNA that are important in cell-to-cell communications. Signaling pathways composed of exosomes, miRNAs and target genes can affect tumor angiogenesis. For example, miR-135b delivered by gastric tumor exosomes was found to promote angiogenesis by inhibiting FOXO1 expression in endothelial cells (Bai et al., 2019). Similarly, miR-130a activates GC angiogenesis by targeting C-MYB in vascular endothelial cells (Yang et al., 2018b).

\section{THE MECHANISM OF RESISTANCE TO CHEMOTHERAPY OR RADIOTHERAPY OF NCRNAS FOR GASTRIC CANCER}

The main cause of death in patients with solid tumors is their eventual development of resistance to one or more chemotherapy drugs, which may eventually lead to metastatic disease. The mechanisms involved in GC resistance to cancer drugs are complex, including decreased apoptosis, increased autophagy, lost cell cycle checkpoint control, accelerated cell proliferation, inactivated signaling pathways and targeted genes, as well as accelerated cancer stem cell (CSC) drug metabolism and activation (Figure 2) (Wei et al., 2020a). Chemotherapy is the main treatment for early and late tumors. However, drug resistance is the main obstacle to cancer treatment, which seriously limits the role of traditional chemotherapy and new biological agents (Broxterman et al., 2009). In recent years, there are more and more studies on ncRNAs, target gene regulation, affecting drug function, pharmacogenomics or drug resistance. For example, according to previous studies, the down-regulation of miR-21 makes cancer cells sensitive to different chemotherapy in vitro, including cisplatin, etoposide and Adriamycin (Seca et al., 2013; Yang et al., 2015; Vanas et al., 2016). On the other hand, some drugs can induce alterations in miR-21 levels: soladosine can inhibit lung cancer cell invasion through miR-21 down-regulation. miR-34a was reported to be downstream of p53 and to function as a tumor suppressor (Welch et al., 2007). It is down-modulated incolorectal cancer (CRC) (Akao et al., 2010). In 5-Fluorouracil (5-FU)resistantcolon cancer cells ectopic expression of miR-34a inhibited cell growth and attenuated the resistance to 5-FU through downregulation of SIRT1 and E2F3, inhibition of LDHA and of c-Kit, thus reducing stem cell factor (SCF)induced migration/invasion (Akao et al., 2011).

\subsection{Apoptosis}

Several ncRNAs affect apoptosis by influencing effective and multifunctional inhibitors of apoptosis, including Bcl-2 (Voss et al., 2010), apoptosis repressor with a caspase recruitment domain (ARC) (Ludwig-Galezowska et al., 2011), MET (Montagne et al., 2015), RhoE (Ongusaha et al., 2006), and AURKB (He et al., 2016); or by influencing enhancers of 
apoptosis, including calpain small subunit 1 (CAPNS1) (Bertoli et al., 2009), PTEN (Zhu et al., 2020), and LRIG1 (Chang et al., 2013). The lncRNA HMGA1P4 was shown to trigger DDP resistance in GC by adjusting the expression levels of genes associated with apoptosis, including those encoding the proteins Bcl-2, Bax, and caspase-3 (Qiao et al., 2020). Enhanced expression of miR-185 was found to increase the chemosensitivity of GC cells by preventing ARC (Li et al., 2014). Upregulation of miR-34a increased the sensitivity of GC cells to DDP by stopping MET, thereby affecting GC cell proliferation and apoptosis (Zhang et al., 2016b). MiR-200c, which targets RhoE, increases cisplatin-induced apoptosis and is therefore considered a potent factor in eliminating chemoresistance (Ghasabi et al., 2019). MiR-let-7, which targets AURKB, increases the cytotoxicity of DDP in SGC7901/DDP cells by inducing apoptosis and increasing sensitivity to chemotherapeutic agents (Han et al., 2018). Inhibition of miR-99a and miR-491 was found to enhance chemosensitivity to cisplatin in human GC cells by increasing CAPNS1 expression (Zhang et al., 2016c). Down-regulation of miR-147 had a positive effect on PTEN, increasing the sensitivity of GC cells to 5-FU by inducing apoptosis (Shen et al., 2018). MiR-4295 negatively regulates LRIG1 expression to activate the EGFR/PI3K/Akt signal pathway, thereby promoting GC cell proliferation and inhibiting DDP-induced GC cell apoptosis (Yan et al., 2018). Several other ncRNAs affect the apoptosis of GC cells through various pathways. For example, circAKT3, which acts as a ceRNA to miR-198, enhances the expression of PIK3R1, activates the PI3K/AKT signaling cascade, and promotes CDDP resistance (Huang et al., 2019). Up-regulating the expression of miR-206, which targets MAPK3 expression, was found to attenuate the proliferation of drug-resistant GC cells, promote apoptosis and reduce DDP resistance (Chen et al., $2019 b$ ). Low expression of miR-135b induced the apoptosis of GC cells through the MST1-mediated MAPK signaling pathway, thus enhancing cell sensitivity to cisplatin (Bai et al., 2019).

\subsection{Autophagy}

Autophagy exhibits different effects in different situations. Protective autophagy inhibition reduces previously activated cell defense mechanisms, increasing cell sensitivity to chemotherapeutic agents. Overactivated autophagy can lead to cell death through solute overactivation, activating another cell death pathway, in addition to apoptosis (Taylor et al., 2018). Autophagy is crucial to the mechanism by which GC cells become resistant to chemotherapy. Abnormal activation of autophagy induced by chemotherapeutic drugs can provide energy to support cancer cells, enhancing resistance to chemotherapy. NcRNAs influence autophagy through autophagy-related genes, including ATG, SQSTM1, GRP78, GABARAPL1, and $R A B 12$. MiR-181a targets $A T G 5$ as a major autophagy-related modulator and reverses cisplatin resistance in GC cells (Zhao et al., 2016). MiR-143 potently inhibits autophagy by decreasing GABARAPL1 (ATG8), thereby modulating chemosensitivity to quercetin (Du et al., 2015). The miR-23b-3p/ATG12/HMGB2/ autophagy regulatory cycle plays a crucial part in multi-drug resistance (MDR) in GC cells. MiR-23b-3p has been shown to inhibit autophagy mediated by ATG12 and HMGB2, sensitizing GC cells to chemotherapy (An et al., 2015). By targeting ATG16L1, miR-874 inhibits autophagy and sensitizes GC cells to chemotherapy (Huang et al., 2018). Impaired autophagic degradation of the IncRNA ARHGAP5-AS1 recruited by SQSTM1 in cancer cells resistant to agents such as DDP, $\mathrm{ADM}$, and 5-FU promotes chemoresistance (Zhu et al., 2019a). MiR-495-3p inhibits autophagy and MDR by downregulating the target gene GRP78 (Chen et al., 2018a). In addition, miR-148a-3p inhibits cellular protective autophagy in DDP-resistant GC cells by suppressing $R A B 12$ expression and mTOR1 activation (Li et al., 2017b).

Interactions among ncRNAs also play a crucial role in autophagy in GC. CircCUL2 decreases autophagy through miR-142-3p/ROCK2 to modulate malignant transformation and cisplatin resistance in GC cells (Peng et al., 2020). CircMCTP2 can reduce the autophagy of platinum-resistant GC cells and inhibit the expression of miR-99a-5p and MTMR3, thus inhibiting cisplatin resistance in these. Moreover, inhibition of miR-99a-5p can sensitize GC cells sensitive to CDDP (Sun et al., 2020). The lncRNA MALAT1, an endogenous competitor of miR-23b-3p RNA, attenuates its inhibition of ATG12 expression, leading to chemotherapyinduced autophagy and resistance to chemotherapy in GC cells (YiRen et al., 2017). The lncRNA MALAT1, which binds to miR$30 \mathrm{e}$ to regulate ATG5 expression, promotes autophagy and inhibits autophagy-related chemotherapy (Zhang et al., 2020c). In addition, the IncRNA MALAT1 has been found to enhance autophagy through the miR-30b/ATG5 axis in HGC-27/CDDP cells, which has a potent effect on autophagy-related CDDP resistance (Xi et al., 2019).

\subsection{MDR Related Pathways}

MDR is the leading cause of chemotherapy failure in cancer treatment. Signaling pathways associated with MDR include the Wnt/ $\beta$-catenin, PI3K/PTEN/Akt/mTOR, TGF- $\beta$, MAPK, and exosome pathways.

\subsubsection{Wnt/ $\beta$-Catenin Pathway}

The Wnt/ $\beta$-catenin pathway is one of the major signaling pathways involved in epithelial-neutral transition (EMT). The EMT-like morphology of cancer cells may be responsible for their chemoresistance and invasion (Chen et al., 2011). MiR-149 promotes 5-FU resistance in GC cells, mainly by targeting TREM2 and activating the $\beta$-catenin pathway (Wang et al., 2020a). Knockdown of the lncRNA HOTAIR and upregulation of miR-34a inhibits DDP resistance in GC cells by inactivating the $\mathrm{PI} 3 \mathrm{~K} / \mathrm{Akt}$ and $\mathrm{Wnt} / \beta$-catenin signal pathways (Cheng et al., 2018a). LincRNA-p21 enhances the sensitivity of GC to radiotherapy by suppressing the $\beta$-catenin signaling pathway (Chen et al., 2019c).

\subsubsection{PI3K/PTEN/Akt/mTOR Pathway}

The PI3K/PTEN/Akt/mTOR signaling pathway plays a prominent part in mediating drug resistance. Poor outcomes in patients with many types of malignancy has been associated with the loss of PTEN, resulting in resistance to new 
chemotherapeutic agents (Keniry and Parsons, 2008). MiR-147 was found to inhibit the PI3K/AKT signaling pathway by directly increasing PTEN expression and enhancing the resistance of GC cells to 5-FU. The miR-20a/LRIG1 axis regulates GC cells through EGFR mediated PI3K/AKT and MAPK/ERK signaling pathways to modulate MDR in GC (Cheng et al., 2018a).

\subsubsection{TGF- $\beta$}

In normal cells and the early stages of cancer, this pathway has tumor-inhibiting functions, including cell cycle arrest and apoptosis. In advanced cancers, however, activation of this pathway can promote tumorigenesis, for example by promoting tumor metastasis (Colak and Ten Dijke, 2017). The TGF- $\beta / Z E B 2$ axis plays an important role in drug resistance of GC, whereas miR-200C overexpression inhibits ZEB1/ZEB2, leading to sensitizing GC cells to trastuzumab (Zhou et al., 2018). MiR-187 enhances the sensitivity of GC cells to cisplatin by inhibiting the transforming growth factor- $\beta$ (TGF$\beta) /$ Smad signaling pathway (Zhu et al., 2019b).

\subsubsection{MAPK}

Triple root-activated protein kinase 3 (MAPK3) plays a key role in the extracellular signal-regulated kinase (ERK)/MAPK pathway. Upregulation of miR-206 can inhibit the proliferation of drug-resistant GC cells, promote apoptosis and reduce DDP resistance by targeting MAPK3 expression (Chen et al., 2019b). Down-regulation of miR-135b leads to inactivation of the MAPK signaling pathway and increases the expression of MST1 and Bax, thus enhancing the sensitivity of GC cells to CDDP. Mir-939 inhibits the growth of GC cells, both in vitro and in vivo, primarily by inhibiting the activated SLC34A2/Raf/MEK/ ERK pathway, and enhances GC cell sensitivity to $5-\mathrm{FU}$ by inducing apoptosis (Zhang et al., 2017b).

\subsubsection{Exosomes}

Exosomes are biologically active nanosized extracellular vesicles that are released by cells into the extracellular space, and play a central role in the initiation and development of intercellular signaling networks (Rajagopal and Harikumar, 2018). Exosomes can also enhance resistance to chemotherapy by exporting drugs or sharing antiapoptotic drugs in cancer cells, thereby interfering with drug metabolism (Abak et al., 2018).

Cancer-associated fibroblasts (CAFs) support tumor progression and drug resistance by secreting various bioactive substances, including exosomes. MiR-522 secreted by CAFs inhibits iron-associated death in GC and ultimately reduces their sensitivity to chemotherapy (Zhang et al., 2020d). MiR21-containing exosomes secreted by tumor-associated macrophages (TAMs) induce DDP resistance in GC (Zheng et al., 2017). MGC803/DDP-derived exosomes deliver miR500a-3p targeting FBXW7 in vitro, enhancing DDP resistance and stem cell properties of MGC803 recipient cells (Lin et al., 2020). MiR-155-5p is enriched in MGC-803R exons and can be delivered to MGC-803S cells (Wang et al., 2019). Exosomes containing miR-106a-5p and miR-421 are highly expressed and modulate TFAP2E methylation-induced chemotherapy (Jingyue et al., 2019). Exosomes containing miR-501 exhibit resistance to doxorubicin by targeting BLID (Liu et al., 2019b). Exosomes secrete nanoparticles with anti-miR-214 activity to reverse GC cell chemoresistance (Wang et al., 2018c). Exosomes containing circPRRX1 enhance doxorubicin resistance by regulating miR-3064-5p/PTPN14 signaling (Table 2) (Wang et al., 2020b).

\subsubsection{Glycolytic Pathway}

Cancer cells undergo glycolysis in the presence of oxygen, which is called the Warburg effect. Accumulated evidence has displayed that the aberrant activation of glycolysis plays an important role in many kinds of diseases via various mechanisms, including the induction of cancer chemotherapy resistance, including GC (Broxterman et al., 2009; Ganapathy-Kanniappan and Geschwind, 2013). A study has determined that microRNA4290 suppresses PDK1-mediated glycolysis to enhance the sensitivity of gastric cancer cell to cisplatin (Qian et al., 2020). Another research has studied that down-regulation of miR-7 in gastric cancer is able to inhibit the proliferation, colony formation, and glycolysis of GC cells owing to its regulation of LDH-A, it also associated with chemoresistance to cisplatin (Jin et al., 2020a).

\subsection{The Resistance Mechanism of ncRNAs in HER2-Positive GC}

HER2 overexpression drives tumorigenesis by creating spontaneous receptor homoplasms or heterogenes with other $E R B B$ family members, thereby generating the expression of active pathogenic downstream signals, such as PI3K/Akt/ mTOR and MAPK, which promote cell proliferation, survival, and angiogenesis (Meric-Bernstam et al., 2019). Trastuzumab, gefitinib, and lapatinib were all shown to have significant curative effects in patients with HER2-positive GC, and these agents have become the key chemotherapy drugs in HER2-positive GC. Silencing of both HER2 and EGFR has been shown to increase tumor chemosensitivity to gefitinib (Wang et al., 2018d).

In HER2-positive GC, miR-494 inhibits cancer-initiating cell phenotypes and reverses resistance to lapatinib by reducing the expression of fibroblast growth factor receptor 2 (FGFR2) (Yu et al., 2018). MiR-143 inhibits the growth of HER2-positive GC cells by inhibiting the KRAS network, including the RNA helicase DDX6 (Tokumaru et al., 2019). The miR-21/PTEN pathway affects the sensitivity of GC cells to trastuzumab by regulating the apoptosis of HER2-positive GC cells (Eto et al., 2014). Overexpression of miR-223 reduced the expression of FBXW7 and the sensitivity of GC cells to terrazumab, whereas inhibition of miR-223 restored the expression of FBXW7 and the sensitivity of GC cells to terrazumab (Table 3) (Eto et al., 2015).

\subsection{Hypoxia}

In addition, ncRNAs affect the sensitivity of GC to chemotherapy by regulating the hypoxia signal pathway. Hypoxia-inducible factor-1 (HIF-1) is the main transcription factor significantly activated by hypoxia (Liu et al., 2008). HIF-1 can inhibit druginduced apoptosis and reduce the accumulation of drugs in cells, resulting in hypoxia-induced drug resistance. The abnormal 
TABLE 2 | Exsomes ncRNAs AND drug resistance.

\begin{tabular}{|c|c|c|c|}
\hline NcRNA & Host cells & Mechanism of function & References \\
\hline miR-522 & Cancer-associated fibroblasts (CAFs) & ferroptosis $\downarrow$;lipid-ROS accumulation $\downarrow$ & Zhang et al. (2020d) \\
\hline $\mathrm{miR}-21$ & tumor-associated macrophages (TAMs) & exosomal transfer;PTEN $\downarrow$ & Zheng et al. (2017) \\
\hline miR-500a-3p & cisplatin-resistant GC cells & stemness properties $\uparrow$ & Lin et al. (2020) \\
\hline miR-155-5p & paclitaxel-resistant GC cells & EMT ;:chemoresistant phenotypes $\uparrow$ & Wang et al. (2019) \\
\hline$m i R-106 a-5 p$ and miR-421 & 5-fluorouracil-resistant GC cells & TFAP2E methylation $\uparrow$ & Jingyue et al. (2019) \\
\hline miR-501 & doxorubicin-resistant GC cells & BH3-like motif-containing protein(BLID) $\uparrow$ & Liu et al. (2019b) \\
\hline miR-214 & HEK293T & potential targets $\uparrow ; a p o p t o s i s \uparrow$ & Wang et al. (2018c) \\
\hline circPRRX1 & doxorubicin-resistant GC cells & 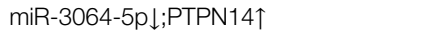 & Wang et al. (2020b) \\
\hline
\end{tabular}

\begin{tabular}{|c|c|c|c|}
\hline ncRNA & Main contents & Mechanism of function & References \\
\hline miR-494 & lapatinib & 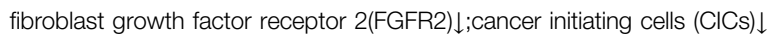 & Yu et al. (2018) \\
\hline $\mathrm{miR}-143$ & growth & KRAS network $\downarrow$;DDX6 RNA helicase $\downarrow$ & Tokumaru et al. (2019) \\
\hline miR-21 & trastuzumab & PTEN $\downarrow ; A K T$ phosphorylation $\uparrow$ & Eto et al. (2014) \\
\hline miR-223 & terrazumab & F-box and WD repeat domain-containing 7 (FBXW7) & Eto et al. (2015) \\
\hline
\end{tabular}

expression of miR-20b, miR-27a, and miR-181a is related to the modulation of the chemotherapy response in GC by HIF-1a (Danza et al., 2016). HIF-1 $\alpha$ induces the expression of miR-27a, which is closely associated with MDR in GC (Zhao et al., 2015). By binding to miR-376a, the lncRNA Nutm2a-AS1 positively modulates GC formation and drug resistance through the regulation of HIF-1a (Wang et al., 2020c).

\section{THE EFFECT OF SOME IMPORTANT NON-CODING RNAS ON GASTRIC CANCER}

Comprehensive and in-depth analyses of several ncRNAs have revealed their roles in GC cell behavior and drug sensitivity (Figure 3).

\subsection{MiR-21}

For example, a large-scale miRnome analysis of 540 samples, including solid tumors, such as GCs found that miR-21 is closely associated with the pathogenesis of solid tumors and poor patient prognosis (Volinia et al., 2006). MiR-21 affects the proliferation, metastasis, apoptosis, stem cell properties, and drug sensitivity of GCs. For example, miR-21-5p provides a favorable in vitro environment for the mesothelial-to-mesenchymal transformation (MMT) of peritoneal metastatic cancer cells by activating the TGF- $\beta /$ Smad pathway (Li et al., 2018b). Chromosomal protein homology (CBX) maintains the stem cell-like properties of GC cells by regulating the p16 and AKTNF- $\kappa B-m i R-21$ pathways (Ni et al., 2018). B cell-specific moloney murine leukemia virus integration site 1 (Bmi-1) actively regulates the stem cell-like properties of GC cells by increasing miR-21, which targets the PTEN/Akt signaling pathway and promotes human GC cell proliferation, migration, and apoptosis (Zhang et al., 2012; Wang et al., 2016; Wang et al., 2018e). The lncRNAs-MEG3 (Dan et al., 2018) and LINC-PINT
(Feng et al., 2019), as well as circHIAT1 (Quan et al., 2020) and circ_0027599 (Han et al., 2021), are able to bind miR-21 and play a negative role in GC progression. Exosomes carrying miR-21 can be transferred from macrophages to GC cells, inhibiting cell apoptosis, enhancing the activation of the PI3K/AKT signaling pathway, and inducing cisplatin resistance by down-regulating PTEN. MiR-21 enhances cell survival by targeting PTEN, inducing resistance to doxorubicin and cisplatin (Yang et al., 2013; Chen et al., 2018b).

Serum miR-21 is also a biomarker and a key regulator of the immune response in GC. Serum miR-21 concentration can indicate tumor recurrence in young GC patients (Park et al., 2016). MiR-21 is not only highly expressed in GCs, but is also highly expressed in the gastric juice of GC patients, affecting their prognosis (Motoyama et al., 2010; Zheng et al., 2011; Cui et al., 2013; Kim et al., 2013; Wu et al., 2015; Sierzega et al., 2017; Pereira et al., 2019; Zhang et al., 2020e). MiR-21 may also be a potential indictor of chemoresistance patients with metastatic GC (MGC) (Zheng et al., 2019). The overexpression of miR-21 increases the percentage of Th17 cells and reduces the percentage of Treg cells, resulting in an imbalance in the $\mathrm{PD}-1 / \mathrm{PD}-\mathrm{L} 1$ pathway and regulating immune responses in GC (Liu et al., 2018). Synthetic circRNAs that target miR-21 can induce therapeutic dysfunction, inhibiting the proliferation of cancer cells and the activity of miR-21 against downstream protein targets, including the tumor protein DAXX (Qi et al., 2017b).

\subsection{MiR-34a}

MiR-34a was found to be a classic tumor suppressor miRNA in several malignancies (Hermeking, 2007). MiR-34a has also been shown to inhibit the growth, invasion, and metastasis of GC by targeting the expression of PDGFR and MET (Peng et al., 2014). Silencing of miR-34a is also partly responsible for activation of the cancer-promoting molecule IGF2BP3 (Zhou et al., 2017b). The novel microprotein miPEP133 encoded by the miR-34a precursor enhances $p 53$ transcription and miR-34a expression, 


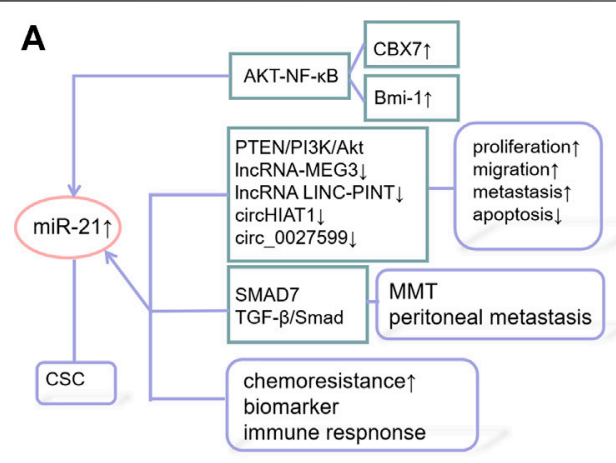

B
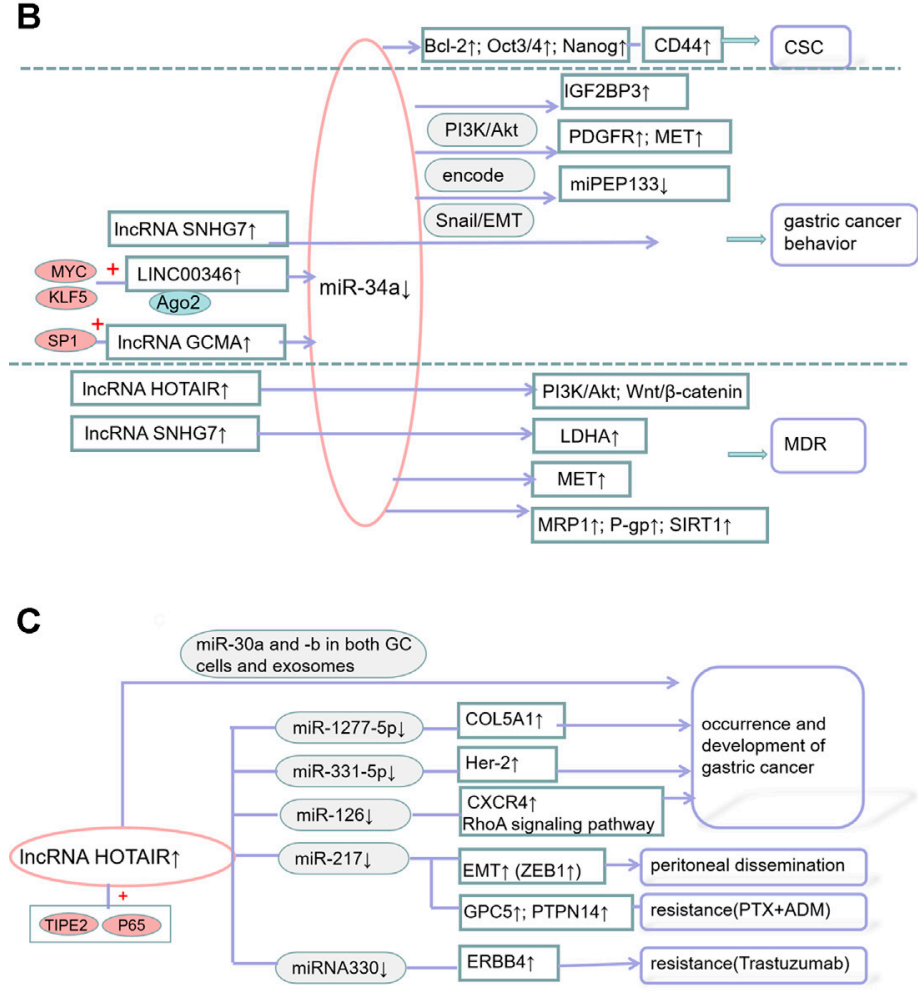

D

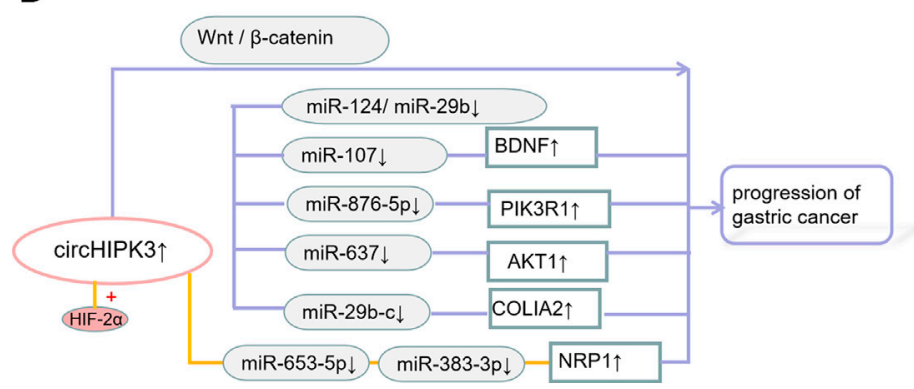

FIGURE 3 | (A) The mechanism of miR-21 in GC; (B) The mechanism of miR-34a in GC; (C) The mechanism of IncRNA HOTAIR in GC; (D) The mechanism of circular RNA circHIPK3 in GC. 
thereby exerting a tumor suppressor effect (Kang et al., 2020). SNHG7 increases the invasion and migration of GC cells through the miR-34a-Snail-EMT axis (Zhang et al., 2020f). LINC00346 binds to and neutralizes miR-34a-5p, with KLF5 and MYC/ LINC00346/miR-34a-5p being key effectors of GC tumorigenesis and progression (Xu et al., 2019a). SP1-activated lncRNA GCMA is a ceRNA that adsorbs miR-124 enhancing tumor metastasis and reducing GC progression (Tian et al., 2020b). Bmi-1 can actively regulate the stem cell-like properties of GC cells by increasing miR-34a expression (Wang et al., 2016). MiR-34a can regulate the sensitivity of human GC cells to DDP by targeting MET (Zhang et al., 2016b). MiR-34a-5p regulates the expression of Sirtuin 1 (SIRT1), P-glycoprotein (P-gp), and multidrug resistancerelated protein 1 (MRP1) by directly binding to the $3^{\prime}$ untranslated region (UTR) of SIRT1, thereby reversing the MDR of GC cells (Deng et al., 2021).

The lncRNAs HOTIAR and SNHG7 adsorb miR-34a. AntimiR-34a antibody was found to reverse the effect of si-HOTAIR on DDP resistance, on apoptosis-related genes, and on the PI3K/ Akt, and Wnt/ $\beta$-catenin signaling pathways in anti-DDPGC cells, suggesting that the effect of HOTAIR depends on miR-34a (Cheng et al., 2018a). The level of the lncRNA SNHG7 negatively correlates with that of miR-34a, desensitizing GC cells to cisplatin (Pei et al., 2021). In addition, miR-34a was found to affect the expression of cancer stem cells (CSCs) overexpressing CD44, leading to tumorigenesis and recurrence, while inhibiting the proliferation, metastasis, and survival of CD44-positive CSCs (Jang et al., 2016).

\subsection{LncRNA HOTAIR}

Overexpression of the lncRNA HOTAIR is a biomarker for poor prognosis in patients with GC, as it may enhance malignant phenotype (Feng and Huang, 2017). High expression of HOTAIR is associated with tumor differentiation, lymph node and distant metastases, and higher clinical stage (Xu et al., 2019b). HOTAIR promotes GC by altering miRNA levels in cells and exosomes (Zhang et al., 2020g). HOTAIR effectively binds to and neutralizes miR-331-3p, thereby regulating the attenuation of HER2 levels and promoting GC progression (Liu et al., 2014). HOTAIR enhances GC growth by binding to a neutralizing miR1277-5p and by up-regulating COL5A1 (Wei et al., 2020b). High HOTAIR expression promotes the proliferation and metastasis of GC through the miR-126/CXCR4 axis and SDF-1/CXCR4 signaling (Xiao et al., 2019). In mice, HOTAIR directly targets miR-217 and combines with the zinc finger electronic box binding home box 1 protein (ZEB1) to inhibit peritoneal diffusion of GC, significantly prolonging survival time (Takei et al., 2020). HOTAIR, which is stimulated by the NF- $\kappa B$ pathway, was found to promote GC progression by enhancing non-resolving inflammation (Zhang et al., 2019d). HOTIAR also affects GC chemoresistance. Overexpression of HOTAIR was found to enhance the resistance of GC cells to paclitaxel (PTX) and doxorubicin (ADR) (Wang et al., 2018f). In addition, the HOTAIR-miR-330-ERBB4 regulatory network with miRNA330 as its core was found to enhance the sensitivity of tumor cells to trastuzumab (Bie et al., 2020).

\subsection{Circular RNA circHIPK3}

CircHIPK 3 is generated from exon 2 of the gene encoding homeodomain-interacting protein kinase 3 (HIPK3) (Xie et al., 2020b; Wen et al., 2020). The expression of circHIPK3 was found to be significantly higher in GC tissues than in adjacent normal tissues, suggesting that increased CircHIPK3 expression was associated with poor prognosis (Liu and Xu, 2019). CircHIPK3 forms an axis with miR-124 and miR-29b to that target COL1A1, COL4A1, and CDK6, which function in different histological growth patterns (Cheng et al., 2018b). CircHIPK3 adsorbs miR107 (Wei et al., 2020c), miR-876-5p (Li et al., 2020c), miR-637 (Yang et al., 2021), playing a pivotal role in GC tumorigenesis and development. Hif-2 $\alpha$ is upregulated in hypoxic drug-resistant GC (HRGC) cells under a long-term hypoxic microenvironment and promotes GC metastasis through the miR-653-5p/miR-338-3PNRP1 axis (Jin et al., 2020b). These circRNAs, which form complex RBP-circRNA-miRNA-mRNA interaction networks, such as the circHIPK3/miR-29b-c/COL1A2 network, are involved in GC development, progression, and reduced sensitivity to chemotherapy (Pereira et al., 2020).

\section{CLINICAL TRIALS OF NCRNAS}

Clinical studies are underway to evaluate applications of ncRNAs. For example, a study of tumor and adjacent normal tissues collected from 60 prospectively selected patients with GC found that Hsa_circ_0000745 played a crucial role in tumor development. A diagnostic index, involving plasma concentrations of ncRNAs and CEA, has been shown promising in the identifying patients with malignant tumors (Huang et al., 2017b). Four common miRNA polymorphisms, miR-146aC $>\mathrm{G}$, miR-149T $>\mathrm{C}$, miR$196 \mathrm{a} 2 \mathrm{~T}>\mathrm{C}$, and miR-499A > G, were found to be associated with susceptibility to and prognosis of GC in the Korean population (Ahn et al., 2013). A prospective clinical trial of GC patients treated with oxaliplatin/capecitabine (XELOX) chemotherapy found that plasma concentrations of miR-17-92 were closely associated with the progression of advanced GC and the effectiveness of XELOX chemotherapy (Fan et al., 2018). A study in 2010-2017 of Pralatrex and oxaliplatin in the treatment of unresectable or metastatic esophageal, gastric, or gastroesophageal junction carcinoma compared the mean expression of miR-215-5p in tumor tissues of responders and nonresponders using microprocessing devices of a gene chip and obtained reliable results. Another study in Singapore aims to test the predictive ability of multiple blood biomarkers, such as miRNAs, to detect early signs of disease at a stage at which tumors can be prevented or cured (Song and Meltzer, 2012).

Ongoing studies are evaluating the mechanisms of action of lncRNAs in gastrointestinal diseases and their possible relationships with Helicobacter pylori infection. In addition, levels of expression of miRNAs in GC tissue and blood and their association with responses to chemotherapy are being determined by next-generation sequencing, with validation by qRT-PCR, in multiple independent patient cohorts. The relationships between ncRNAs and cancer immune checkpoints are being explored to identify new uses for 
ncRNAs in cancer immunotherapy, and differences in exosomal protein/ncRNA components are being evaluated in patients before and after combination chemotherapy with Apatinib and anti-PD-1 antibody.

\section{DISCUSSION}

Findings to date have shown that ncRNAs are extensively involved in gene regulatory networks. Many ncRNAs do not act as a single link, but as branching points with broad outputs that affect regulatory networks containing target genes or related signaling pathways. In GCs, ncRNAs have been identified as carcinogenic drivers and tumor suppressors.

In conclusion, this review provides strong evidence that ncRNAs can act as biomarkers for the diagnosis, prognosis, and chemotherapy resistance of GCs. Many studies to date have shown that ncRNAs play complex and important roles in GC proliferation, invasion, apoptosis, and angiogenesis. These ncRNAs or their resulting ceRNAs can alter the expression of target genes and/or affect classic signaling pathways. ncRNAs also participate in the regulation of resistance to radiotherapy and chemotherapy by affecting the expression of signaling pathways related to apoptosis and autophagy, and by regulating MDRrelated genes and pathways. ncRNAs can also form networks in GC. Taken together, these findings indicate that targeting ncRNAs may be a promising method of enhancing sensitivity to chemotherapy, thereby improving the efficacy of treatment, in patients with GC. Studies evaluating the effects of ncRNAs on immunotherapy in GC are currently ongoing. The stability of ncRNAs in the circulation makes them suitable diagnostic and

\section{REFERENCES}

Abak, A., Abhari, A., and Rahimzadeh, S. (2018). Exosomes in Cancer: Small Vesicular Transporters for Cancer Progression and Metastasis, Biomarkers in Cancer Therapeutics. PeerJ 6, e4763. doi:10.7717/peerj.4763

Ahn, D. H., Rah, H., Choi, Y. K., Jeon, Y. J., Min, K. T., Kwack, K., et al. (2013). Association of the miR-146aC $>$ G, miR-149T $>C$, miR-196a2T $>C$, and miR499A > G Polymorphisms with Gastric Cancer Risk and Survival in the Korean Population. Mol. Carcinog 52 (Suppl. 1), E39-E51. doi:10.1002/mc.21962

Akao, Y., Nakagawa, Y., Hirata, I., Iio, A., Itoh, T., Kojima, K., et al. (2010). Role of Anti-oncomirs miR-143 and -145 in Human Colorectal Tumors. Cancer Gene Ther. 17, 398-408. doi:10.1038/cgt.2009.88

Akao, Y., Noguchi, S., Iio, A., Kojima, K., Takagi, T., and Naoe, T. (2011). Dysregulation of microRNA-34a Expression Causes Drug-Resistance to 5FU in Human colon Cancer DLD-1 Cells. Cancer Lett. 300, 197-204. doi:10.1016/j.canlet.2010.10.006

An, Y., Zhang, Z., Shang, Y., Jiang, X., Dong, J., Yu, P., et al. (2015). miR-23b-3p Regulates the Chemoresistance of Gastric Cancer Cells by Targeting ATG12 and HMGB2. Cell Death Dis 6, e1766. doi:10.1038/cddis.2015.123

Aravin, A. A., Sachidanandam, R., Girard, A., Fejes-Toth, K., and Hannon, G. J. (2007). Developmentally Regulated piRNA Clusters Implicate MILI in Transposon Control. Science 316, 744-747. doi:10.1126/science.1142612

Bai, M., Li, J., Yang, H., Zhang, H., Zhou, Z., Deng, T., et al. (2019). miR-135b Delivered by Gastric Tumor Exosomes Inhibits FOXO1 Expression in Endothelial Cells and Promotes Angiogenesis. Mol. Ther. 27, 1772-1783. doi:10.1016/j.ymthe.2019.06.018

Bai, Y., and Li, S. (2020). Long Noncoding RNA OIP5-AS1 Aggravates Cell Proliferation, Migration in Gastric Cancer by Epigenetically Silencing prognostic markers for most cancers and determination of their concentrations in serum may be useful in the personalized management of patients. Better understanding of these ncRNAs and their target genes may provide new perspectives for the development of more complex and effective therapeutic agents for the treatment of GC. Techniques and tools to develop ncRNA-targeted and ncRNA-based drugs have been widely used in cancer treatment. Strategies including antisense oligonucleotide (ASO), RNA interference (RNAi) and CRISPR/Cas9 have been proposed to up-regulate the tumor inhibition of ncRNA using gene silencing techniques (Chen et al., 2021b). However, barriers to the translation of nucleic acid-based therapeutics into the clinic are related to their stability, specificity, delivery, and toxicity issues, such as "on-target" and "off-target" side effects (Hueso et al., 2021). It is very important to conduct further in vitro and in vivo studies and clinical studies on the efficacy and safety of ncRNA to achieve precision medicine.

\section{AUTHOR CONTRIBUTIONS}

YY and XL wrote the review article. XQ participated in modification. LY and RW reviewed the manuscript. All authors read and approved the final manuscript.

\section{FUNDING}

The work was supported by grants from the National Natural Science Foundation of China (Nos. 81772995 and 81472266); Natural Science Foundation of Jiangsu Province (BK20191208).

NLRP6 Expression via Binding EZH2. J. Cel Biochem 121, 353-362. doi:10.1002/jcb.29183

Bertoli, C., Copetti, T., Lam, E. W.-F., Demarchi, F., and Schneider, C. (2009). Calpain Small-1 Modulates Akt/FoxO3A Signaling and Apoptosis through PP2A. Oncogene 28, 721-733. doi:10.1038/onc.2008.425

Bie, L., Luo, S., Li, D., Wei, Y., Mu, Y., Chen, X., et al. (2020). HOTAIR Competitively Binds MiRNA330 as a Molecular Sponge to Increase the Resistance of Gastric Cancer to Trastuzumab. Ccdt 20, 700-709. doi:10.2174/1568009620666200504114000

Bray, F., Ferlay, J., Soerjomataram, I., Siegel, R. L., Torre, L. A., and Jemal, A. (2018). Global Cancer Statistics 2018: GLOBOCAN Estimates of Incidence and Mortality Worldwide for 36 Cancers in 185 Countries. CA: A Cancer J. Clinicians 68, 394-424. doi:10.3322/caac.21492

Broxterman, H. J., Gotink, K. J., and Verheul, H. M. W. (2009). Understanding the Causes of Multidrug Resistance in Cancer: a Comparison of Doxorubicin and Sunitinib. Drug Resist. Updates 12, 114-126. doi:10.1016/j.drup.2009.07.001

Cai, J., Wang, D., Bai, Z.-G., Yin, J., Zhang, J., and Zhang, Z.-T. (2017). The Long Noncoding RNA XIAP-AS1 Promotes XIAP Transcription by XIAP-AS1 Interacting with $\mathrm{Sp} 1$ in Gastric Cancer Cells. PLoS One 12, e0182433. doi:10.1371/journal.pone.0182433

Cao, C., Xu, Y., Du, K., Mi, C., Yang, C., Xiang, L., et al. (2019). LINC01303 Functions as a Competing Endogenous RNA to Regulate EZH2 Expression by Sponging miR-101-3p in Gastric Cancer. J. Cel Mol Med 23, 7342-7348. doi: $10.1111 /$ jcmm. 14593

Carmeliet, P., and Jain, R. K. (2011). Molecular Mechanisms and Clinical Applications of Angiogenesis. Nature 473, 298-307. doi:10.1038/nature10144 Carthy, C. M., Yanagawa, B., Luo, H., Granville, D. J., Yang, D., Cheung, P., et al. (2003). Bcl-2 and Bcl-xL Overexpression Inhibits Cytochrome C Release, Activation of Multiple Caspases, and Virus Release Following 
Coxsackievirus B3 Infection. Virology 313, 147-157. doi:10.1016/s00426822(03)00242-3

Carvalho, J., van Grieken, N. C., Pereira, P. M., Sousa, S., Tijssen, M., Buffart, T. E., et al. (2012). Lack of microRNA-101 Causes E-Cadherin Functional Deregulation through EZH2 Up-Regulation in Intestinal Gastric Cancer. J. Pathol. 228, 31-44. doi:10.1002/path.4032

Chang, L., Shi, R., Yang, T., Li, F., Li, G., Guo, Y., et al. (2013). Restoration of LRIG1 Suppresses Bladder Cancer Cell Growth by Directly Targeting EGFR Activity. J. Exp. Clin. Cancer Res. 32, 101. doi:10.1186/1756-9966-32-101

Chen, J., Zhou, C., Li, J., Xiang, X., Zhang, L., Deng, J., et al. (2018). miR-21-5p $\mathrm{C}$-onfers D-oxorubicin R-esistance in $\mathrm{G}$-astric $\mathrm{C}$-ancer C-ells by $\mathrm{T}$-argeting PTEN and TIMP3. Int. J. Mol. Med. 41, 1855-1866. doi:10.3892/ ijmm.2018.3405

Chen, L., Yuan, D., Yang, Y., and Ren, M. (2019). LincRNA-p21 Enhances the Sensitivity of Radiotherapy for Gastric Cancer by Targeting the $\beta$-catenin Signaling Pathway. J. Cel Biochem 120, 6178-6187. doi:10.1002/jcb.27905

Chen, R. Y., Ju, Q., Feng, L. M., Yuan, Q., and Zhang, L. (2019). The Carcinogenic Complex lncRNA FOXP4-AS1/EZH2/LSD1 Accelerates Proliferation, Migration and Invasion of Gastric Cancer. Eur. Rev. Med. Pharmacol. Sci. 23, 8371-8376. doi:10.26355/eurrev_201910_19148

Chen, S., Wu, J., Jiao, K., Wu, Q., Ma, J., Chen, D., et al. (2018). MicroRNA-495-3p Inhibits Multidrug Resistance by Modulating Autophagy through GRP78/ mTOR axis in Gastric Cancer. Cel Death Dis 9, 1070. doi:10.1038/s41419018-0950-x

Chen, X., Lingala, S., Khoobyari, S., Nolta, J., Zern, M. A., and Wu, J. (2011). Epithelial Mesenchymal Transition and Hedgehog Signaling Activation Are Associated with Chemoresistance and Invasion of Hepatoma Subpopulations. J. Hepatol. 55, 838-845. doi:10.1016/j.jhep.2010.12.043

Chen, X., Zhang, S., Du, K., Zheng, N., Liu, Y., Chen, H., et al. (2021). Gastric Cancer-Secreted Exosomal X26nt Increases Angiogenesis and Vascular Permeability by Targeting VE-cadherin. Cancer Sci. 112, 1839-1852. doi:10.1111/cas.14740

Chen, Y., Li, Z., Chen, X., and Zhang, S. (2021). Long Non-coding RNAs: From Disease Code to Drug Role. Acta Pharmaceutica Sinica B 11, 340-354. doi:10.1016/j.apsb.2020.10.001

Chen, Z., Gao, Y. J., Hou, R. Z., Ding, D. Y., Song, D. F., Wang, D. Y., et al. (2019). MicroRNA-206 Facilitates Gastric Cancer Cell Apoptosis and Suppresses Cisplatin Resistance by Targeting MAPK2 Signaling Pathway. Eur. Rev. Med. Pharmacol. Sci. 23, 171-180. doi:10.26355/eurrev_201901_16761

Cheng, C., Qin, Y., Zhi, Q., Wang, J., and Qin, C. (2018). Knockdown of Long Noncoding RNA HOTAIR Inhibits Cisplatin Resistance of Gastric Cancer Cells through Inhibiting the PI3K/Akt and Wnt/ $\beta$-Catenin Signaling Pathways by Up-Regulating miR-34a. Int. J. Biol. Macromolecules 107, 2620-2629. doi:10.1016/j.ijbiomac.2017.10.154

Cheng, J., Zhuo, H., Xu, M., Wang, L., Xu, H., Peng, J., et al. (2018). Regulatory Network of circRNA-miRNA-mRNA Contributes to the Histological Classification and Disease Progression in Gastric Cancer. J. Transl Med. 16, 216. doi:10.1186/s12967-018-1582-8

Chun-Zhi, Z., Lei, H., An-Ling, Z., Yan-Chao, F., Xiao, Y., Guang-Xiu, W., et al. (2010). MicroRNA-221 and microRNA-222 Regulate Gastric Carcinoma Cell Proliferation and Radioresistance by Targeting PTEN. BMC Cancer 10, 367. doi:10.1186/1471-2407-10-367

Colak, S., and Ten Dijke, P. (2017). Targeting TGF- $\beta$ Signaling in Cancer. Trends Cancer 3, 56-71. doi:10.1016/j.trecan.2016.11.008

Cui, H. W., Han, W. Y., Hou, L. N., Yang, L., Li, X., and Su, X. L. (2019). miR-19153p Inhibits Bcl-2 Expression in the Development of Gastric Cancer. Biosci. Rep. 39, BSR20182321. doi:10.1042/BSR20182321

Cui, L., Zhang, X., Ye, G., Zheng, T., Song, H., Deng, H., et al. (2013). Gastric Juice MicroRNAs as Potential Biomarkers for the Screening of Gastric Cancer. Cancer 119, 1618-1626. doi:10.1002/cncr.27903

Dai, J., Wang, J., Yang, L., Xiao, Y., and Ruan, Q. (2015). miR-125a Regulates Angiogenesis of Gastric Cancer by Targeting Vascular Endothelial Growth Factor A. Int. J. Oncol. 47, 1801-1810. doi:10.3892/ijo.2015.3171

Dai, X., Guo, X., Liu, J., Cheng, A., Peng, X., Zha, L., et al. (2019). Circular RNA circGRAMD1B Inhibits Gastric Cancer Progression by Sponging miR-130a-3p and Regulating PTEN and P21 Expression. Aging 11, 9689-9708. doi:10.18632/aging.102414

Dan, J., Wang, J., Wang, Y., Zhu, M., Yang, X., Peng, Z., et al. (2018). LncRNAMEG3 Inhibits Proliferation and Metastasis by Regulating miRNA-21 in
Gastric Cancer. Biomed. Pharmacother. 99, 931-938. doi:10.1016/ j.biopha.2018.01.164

Danza, K., Silvestris, N., Simone, G., Signorile, M., Saragoni, L., Brunetti, O., et al. (2016). Role of miR-27a, miR-181a and miR-20b in Gastric Cancer Hypoxia-Induced Chemoresistance. Cancer Biol. Ther. 17, 400-406. doi:10.1080/15384047.2016.1139244

Deng, X. J., Zheng, H. L., Ke, X. Q., Deng, M., Ma, Z. Z., Zhu, Y., et al. (2021). HsamiR-34a-5p Reverses Multidrug Resistance in Gastric Cancer Cells by Targeting the $3^{\prime}$-UTR of SIRT1 and Inhibiting its Expression. Cell Signal. 84, 110016. doi:10.1016/j.cellsig.2021.110016

Du, F., Feng, Y., Fang, J., and Yang, M. (2015). MicroRNA-143 Enhances Chemosensitivity of Quercetin through Autophagy Inhibition via Target GABARAPL1 in Gastric Cancer Cells. Biomed. Pharmacother. 74, 169-177. doi:10.1016/j.biopha.2015.08.005

Du, J., Liang, Y., Li, J., Zhao, J.-M., and Lin, X.-Y. (2021). Correction to: LINC00858 Knockdown Inhibits Gastric Cancer Cell Growth and Induces Apoptosis through Reducing WNK2 Promoter Methylation. Cell Oncol. 44, 235. doi:10.1007/s13402-020-00574-w

Esteller, M. (2011). Non-coding RNAs in Human Disease. Nat. Rev. Genet. 12, 861-874. doi:10.1038/nrg3074

Esteller, M., and Pandolfi, P. P. (2017). The Epitranscriptome of Noncoding RNAs in Cancer. Cancer Discov. 7, 359-368. doi:10.1158/2159-8290.cd-16-1292

Eto, K., Iwatsuki, M., Watanabe, M., Ida, S., Ishimoto, T., Iwagami, S., et al. (2014). The microRNA-21/PTEN Pathway Regulates the Sensitivity of HER2-Positive Gastric Cancer Cells to Trastuzumab. Ann. Surg. Oncol. 21, 343-350. doi:10.1245/s10434-013-3325-7

Eto, K., Iwatsuki, M., Watanabe, M., Ishimoto, T., Ida, S., Imamura, Y., et al. (2015). The Sensitivity of Gastric Cancer to Trastuzumab Is Regulated by the miR-223/ FBXW7 Pathway. Int. J. Cancer 136, 1537-1545. doi:10.1002/ijc.29168

Fan, B., Shen, C., Wu, M., Zhao, J., Guo, Q., and Luo, Y. (2018). miR-17-92 Cluster Is Connected with Disease Progression and Oxaliplatin/capecitabine Chemotherapy Efficacy in Advanced Gastric Cancer Patients. Medicine (Baltimore) 97, e12007. doi:10.1097/md.0000000000012007

Fang, J., Hong, H., Xue, X., Zhu, X., Jiang, L., Qin, M., et al. (2019). A novel circular RNA, circFAT1(e2), inhibits gastric cancer progression by targeting miR-548g in the cytoplasm and interacting with YBX1 in the nucleus. Cancer Lett. 442, 222-232. doi:10.1016/j.canlet.2018.10.040

Fang, Z., Zhang, L., Liao, Q., Wang, Y., Yu, F., Feng, M., et al. (2017). Regulation of TRIM24 by miR-511 Modulates Cell Proliferation in Gastric Cancer. J. Exp. Clin. Cancer Res. 36, 17. doi:10.1186/s13046-017-0489-1

Fattahi, S., Amjadi-Moheb, F., Tabaripour, R., Ashrafi, G. H., and Akhavan-Niaki, H. (2020). PI3K/AKT/mTOR Signaling in Gastric Cancer: Epigenetics and beyond. Life Sci. 262, 118513. doi:10.1016/j.lfs.2020.118513

Feng, H., Zhang, J., Shi, Y., Wang, L., Zhang, C., and Wu, L. (2019). Long Noncoding RNA LINC-PINT Is Inhibited in Gastric Cancer and Predicts Poor Survival. J. Cel Biochem 120, 9594-9600. doi:10.1002/jcb.28236

Feng, X., and Huang, S. (2017). Effect and Mechanism of Long Noncoding RNAs HOTAIR on Occurrence and Development of Gastric Cancer. J. Cel Biochem 1, 1. doi:10.1002/jcb. 26594

Fuchs, C. S., Tomasek, J., Yong, C. J., Dumitru, F., Passalacqua, R., Goswami, C., et al. (2014). Ramucirumab Monotherapy for Previously Treated Advanced Gastric or Gastro-Oesophageal junction Adenocarcinoma (REGARD): an International, Randomised, Multicentre, Placebo-Controlled, Phase 3 Trial. The Lancet 383, 31-39. doi:10.1016/s0140-6736(13)61719-5

Gan, L., Xu, M., Hua, R., Tan, C., Zhang, J., Gong, Y., et al. (2018). The Polycomb Group Protein EZH2 Induces Epithelial-Mesenchymal Transition and Pluripotent Phenotype of Gastric Cancer Cells by Binding to PTEN Promoter. J. Hematol. Oncol. 11, 9. doi:10.1186/s13045-017-0547-3

Ganapathy-Kanniappan, S., and Geschwind, J.-F. H. (2013). Tumor Glycolysis as a Target for Cancer Therapy: Progress and Prospects. Mol. Cancer 12, 152. doi:10.1186/1476-4598-12-152

G.B.D.S.C. Collaborators (2020). The Global, Regional, and National burden of Stomach Cancer in 195 Countries, 1990-2017: a Systematic Analysis for the Global Burden of Disease Study 2017. Lancet Gastroenterol. Hepatol. 5, 42-54. doi:10.1016/S2468-1253(19)30328-0

Ghasabi, M., Majidi, J., Mansoori, B., Mohammadi, A., Shomali, N., Shirafkan, N., et al. (2019). The Effect of Combined miR-200c Replacement and Cisplatin on Apoptosis Induction and Inhibition of Gastric Cancer Cell Line Migration. J. Cel Physiol 234, 22581-22592. doi:10.1002/jcp.28823 
Group, G., Paoletti, X., Oba, K., Burzykowski, T., Michiels, S., Ohashi, Y., et al. (2010). Benefit of Adjuvant Chemotherapy for Resectable Gastric Cancer: a Meta-Analysis. JAMA 303, 1729-1737. doi:10.1001/jama.2010.534

Guo, L., Bai, H., Zou, D., Hong, T., Liu, J., Huang, J., et al. (2014). The Role of microRNA-133b and its Target Gene FSCN1 in Gastric Cancer. J. Exp. Clin. Cancer Res. 33, 99. doi:10.1186/s13046-014-0099-0

Guo, T., Zhang, Y., Qu, X., Che, X., Li, C., Fan, Y., et al. (2018). miR-200a Enhances TRAIL-Induced Apoptosis in Gastric Cancer Cells by Targeting A20. Cell Biol Int 42, 506-514. doi:10.1002/cbin.10924

Han, H., Wang, S., Meng, J., Lyu, G., Ding, G., Hu, Y., et al. (2020). Long Noncoding RNA PART1 Restrains Aggressive Gastric Cancer through the Epigenetic Silencing of PDGFB via the PLZF-Mediated Recruitment of EZH2. Oncogene 39, 6513-6528. doi:10.1038/s41388-020-01442-5

Han, J., Yang, Z., Zhao, S., Zheng, L., Tian, Y., and Lv, Y. (2021). Circ_0027599 Elevates RUNX1 Expression via Sponging miR-21-5p on Gastric Cancer Progression. Eur. J. Clin. Invest. 51 (11), e13592. doi:10.1111/eci.13592

Han, X., Zhang, J.-J., Han, Z.-Q., Zhang, H.-B., and Wang, Z.-A. (2018). Let-7b Attenuates Cisplatin Resistance and Tumor Growth in Gastric Cancer by Targeting AURKB. Cancer Gene Ther. 25, 300-308. doi:10.1038/s41417-0180048-8

Hanahan, D., and Weinberg, R. A. (2000). The Hallmarks of Cancer. Cell 100, 57-70. doi:10.1016/s0092-8674(00)81683-9

He, L., and Hannon, G. J. (2004). MicroRNAs: Small RNAs with a Big Role in Gene Regulation. Nat. Rev. Genet. 5, 522-531. doi:10.1038/nrg1379

He, S.-J., Shu, L.-P., Zhou, Z.-W., Yang, T., Duan, W., Zhang, X., et al. (2016). Inhibition of Aurora Kinases Induces Apoptosis and Autophagy via AURKB/ p70S6K/RPL15 axis in Human Leukemia Cells. Cancer Lett. 382, 215-230. doi:10.1016/j.canlet.2016.08.016

Hermeking, H. (2007). p53 Enters the microRNA World. Cancer Cell 12, 414-418. doi:10.1016/j.ccr.2007.10.028

Hiki, N., Nunobe, S., Kubota, T., and Jiang, X. (2013). Function-preserving Gastrectomy for Early Gastric Cancer. Ann. Surg. Oncol. 20, 2683-2692. doi:10.1245/s10434-013-2931-8

Hu, X., Wang, Y., Liang, H., Fan, Q., Zhu, R., Cui, J., et al. (2017). miR-23a/b Promote Tumor Growth and Suppress Apoptosis by Targeting PDCD4 in Gastric Cancer. Cel Death Dis 8, e3059. doi:10.1038/cddis.2017.447

Huang, H., Tang, J., Zhang, L., Bu, Y., and Zhang, X. (2018). miR-874 Regulates Multiple-Drug Resistance in Gastric Cancer by Targeting ATG16L1. Int. J. Oncol. 53, 2769-2779. doi:10.3892/ijo.2018.4593

Huang, M., He, Y.-R., Liang, L.-C., Huang, Q., and Zhu, Z.-Q. (2017). Circular RNA Hsa_circ_0000745 May Serve as a Diagnostic Marker for Gastric Cancer. Wjg 23, 6330-6338. doi:10.3748/wjg.v23.i34.6330

Huang, M., Hou, J., Wang, Y., Xie, M., Wei, C., Nie, F., et al. (2017). Long Noncoding RNA LINC00673 Is Activated by SP1 and Exerts Oncogenic Properties by Interacting with LSD1 and EZH2 in Gastric Cancer. Mol. Ther. 25, 1014-1026. doi:10.1016/j.ymthe.2017.01.017

Huang, X., Li, Z., Zhang, Q., Wang, W., Li, B., Wang, L., et al. (2019). Circular RNA AKT3 Upregulates PIK3R1 to Enhance Cisplatin Resistance in Gastric Cancer via miR-198 Suppression. Mol. Cancer 18, 71. doi:10.1186/s12943-019-0969-3

Hueso, M., Mallen, A., Sune-Pou, M., Aran, J. M., Sune-Negre, J. M., and Navarro, E. (2021). ncRNAs in Therapeutics: Challenges and Limitations in Nucleic Acid-Based Drug Delivery. Int. J. Mol. Sci. 22. doi:10.3390/ijms222111596

Jang, E., Kim, E., Son, H.-Y., Lim, E.-K., Lee, H., Choi, Y., et al. (2016). Nanovesiclemediated Systemic Delivery of microRNA-34a for CD44 Overexpressing Gastric Cancer Stem Cell Therapy. Biomaterials 105, 12-24. doi:10.1016/ j.biomaterials.2016.07.036

Jin, H.-F., Wang, J.-F., Shao, M., Zhou, K., Ma, X., and Lv, X.-P. (2020). DownRegulation of miR-7 in Gastric Cancer Is Associated with Elevated LDH-A Expression and Chemoresistance to Cisplatin. Front. Cel Dev. Biol. 8, 555937. doi:10.3389/fcell.2020.555937

Jin, Y., Che, X., Qu, X., Li, X., Lu, W., Wu, J., et al. (2020). CircHIPK3 Promotes Metastasis of Gastric Cancer via miR-653-5p/miR-338-3p-NRP1 Axis under a Long-Term Hypoxic Microenvironment. Front. Oncol. 10, 1612. doi:10.3389/ fonc. 2020.01612

Jingyue, S., Xiao, W., Juanmin, Z., Wei, L., Daoming, L., and Hong, X. (2019). TFAP2E Methylation Promotes 5fluorouracil Resistance via Exosomal miR106a5p and miR421 in Gastric Cancer MGC803 Cells. Mol. Med. Rep. 20, 323-331.
Kang, M., Tang, B., Li, J., Zhou, Z., Liu, K., Wang, R., et al. (2020). Identification of miPEP133 as a Novel Tumor-Suppressor Microprotein Encoded by miR-34a Pri-miRNA. Mol. Cancer 19, 143. doi:10.1186/s12943-020-01248-9

Kang, Y.-K., Boku, N., Satoh, T., Ryu, M.-H., Chao, Y., Kato, K., et al. (2017). Nivolumab in Patients with Advanced Gastric or Gastro-Oesophageal junction Cancer Refractory to, or Intolerant of, at Least Two Previous Chemotherapy Regimens (ONO-4538-12, ATTRACTION-2): a Randomised, Double-Blind, Placebo-Controlled, Phase 3 Trial. The Lancet 390, 2461-2471. doi:10.1016/ s0140-6736(17)31827-5

Keniry, M., and Parsons, R. (2008). The Role of PTEN Signaling Perturbations in Cancer and in Targeted Therapy. Oncogene 27, 5477-5485. doi:10.1038/ onc. 2008.248

Kim, B.-H., Hong, S. W., Kim, A., Choi, S. H., and Yoon, S. O. (2013). Prognostic Implications for High Expression of Oncogenic microRNAs in Advanced Gastric Carcinoma. J. Surg. Oncol. 107, 505-510. doi:10.1002/jso.23271

Kogo, R., Mimori, K., Tanaka, F., Komune, S., and Mori, M. (2011). Clinical Significance of miR-146a in Gastric Cancer Cases. Clin. Cancer Res. 17, 4277-4284. doi:10.1158/1078-0432.ccr-10-2866

Li, B., Jin, M., Cao, F., Li, J., Wu, J., Xu, L., et al. (2020). Hsa_circ_0017639 Expression Promotes Gastric Cancer Proliferation and Metastasis by Sponging miR-224-5p and Upregulating USP3. Gene 750, 144753. doi:10.1016/ j.gene.2020.144753

Li, B., Wang, W., Li, Z., Chen, Z., Zhi, X., Xu, J., et al. (2017). MicroRNA-148a-3p Enhances Cisplatin Cytotoxicity in Gastric Cancer through Mitochondrial Fission Induction and Cyto-Protective Autophagy Suppression. Cancer Lett. 410, 212-227. doi:10.1016/j.canlet.2017.09.035

Li, C., Deng, L., Zhi, Q., Meng, Q., Qian, A., Sang, H., et al. (2016). MicroRNA-183 Functions as an Oncogene by Regulating PDCD4 in Gastric Cancer. Acamc 16, 447-455. doi:10.2174/1871520615666150914114237

Li, Q., Li, B., Li, Q., Wei, S., He, Z., Huang, X., et al. (2018). Exosomal miR-21-5p Derived from Gastric Cancer Promotes Peritoneal Metastasis via MesothelialTo-Mesenchymal Transition. Cel Death Dis 9, 854. doi:10.1038/s41419-0180928-8

Li, Q., Tian, Y., Liang, Y., and Li, C. (2020). CircHIPK3/miR-876-5p/PIK3R1 axis Regulates Regulation Proliferation, Migration, Invasion, and Glutaminolysis in Gastric Cancer Cells. Cancer Cel Int 20, 391. doi:10.1186/s12935-020-01455-w

Li, Q., Wang, J.-X., He, Y.-Q., Feng, C., Zhang, X.-J., Sheng, J.-Q., et al. (2014). MicroRNA-185 Regulates Chemotherapeutic Sensitivity in Gastric Cancer by Targeting Apoptosis Repressor with Caspase Recruitment Domain. Cel Death Dis 5, e1197. doi:10.1038/cddis.2014.148

Li, S., Sun, M. Y., and Su, X. (2019). MiR-885-5p Promotes Gastric Cancer Proliferation and Invasion through Regulating YPEL1. Eur. Rev. Med. Pharmacol. Sci. 23, 7913-7919. doi:10.26355/eurrev_201909_19005

Li, X., Yan, X., Wang, F., Yang, Q., Luo, X., Kong, J., et al. (2019). Down-regulated IncRNA SLC25A5-AS1 Facilitates Cell Growth and Inhibits Apoptosis via miR19a-3p/PTEN/PI3K/AKT Signalling Pathway in Gastric Cancer. J. Cel Mol Med 23, 2920-2932. doi:10.1111/jcmm.14200

Li, Y., Li, D., Zhao, M., Huang, S., Zhang, Q., Lin, H., et al. (2018). Long Noncoding RNA SNHG6 Regulates P21 Expression via Activation of the JNK Pathway and Regulation of EZH2 in Gastric Cancer Cells. Life Sci. 208, 295-304. doi:10.1016/ j.lfs.2018.07.032

Li, Y., Wu, Z., Yuan, J., Sun, L., Lin, L., Huang, N., et al. (2017). Long Non-coding RNA MALAT1 Promotes Gastric Cancer Tumorigenicity and Metastasis by Regulating Vasculogenic Mimicry and Angiogenesis. Cancer Lett. 395, 31-44. doi:10.1016/j.canlet.2017.02.035

Li, Y., Yan, J., Wang, Y., Wang, C., Zhang, C., and Li, G. (2020). LINC00240 Promotes Gastric Cancer Cell Proliferation, Migration and EMT via the miR -124-3p/DNMT3B axis. Cell Biochem Funct 38, 1079-1088. doi:10.1002/ cbf. 3551

Li, Z., Fan, H., Cao, J., Sun, G., Sen Wang, W., Lv, J., et al. (2021). Natriuretic Peptide Receptor a Promotes Gastric Malignancy through Angiogenesis Process. Cel Death Dis 12, 968. doi:10.1038/s41419-021-04266-7

Liang, H., Wang, F., Chu, D., Zhang, W., Liao, Z., Fu, Z., et al. (2016). miR-93 Functions as an oncomiR for the Downregulation of PDCD4 in Gastric Carcinoma. Sci. Rep. 6, 23772. doi:10.1038/srep23772

Liang, L.-C., Liu, L.-Q., Liu, L., Liu, D.-L., He, Y.-R., Wan, X., et al. (2021). Long Non-coding RNA BX357664 Inhibits Gastric Cancer Progression by Sponging 
miR-183a-3p to Regulate the PTEN Expression and PI3K/AKT Pathway. Food Chem. Toxicol. 150, 112069. doi:10.1016/j.fct.2021.112069

Lim, S.-C., Jeon, H. J., Kee, K. H., Lee, M. J., Hong, R., and Han, S. I. (2017). Andrographolide Induces Apoptotic and Non-apoptotic Death and Enhances Tumor Necrosis Factor-Related Apoptosis-Inducing Ligand-Mediated Apoptosis in Gastric Cancer Cells. Oncol. Lett. 13, 3837-3844. doi:10.3892/ ol.2017.5923

Lin, H., Zhang, L., Zhang, C., and Liu, P. (2020). Exosomal MiR-500a-3p Promotes Cisplatin Resistance and Stemness via Negatively Regulating FBXW7 in Gastric Cancer. J. Cel Mol Med 24, 8930-8941. doi:10.1111/jcmm.15524

Lin, L., Xiao, J., Shi, L., Chen, W., Ge, Y., Jiang, M., et al. (2019). STRA6 Exerts Oncogenic Role in Gastric Tumorigenesis by Acting as a Crucial Target of miR873. J. Exp. Clin. Cancer Res. 38, 452. doi:10.1186/s13046-019-1450-2

Liu, L., Ning, X., Sun, L., Zhang, H., Shi, Y., Guo, C., et al. (2008). Hypoxiainducible Factor-1 Alpha Contributes to Hypoxia-Induced Chemoresistance in Gastric Cancer. Cancer Sci. 99, 121-128. doi:10.1111/j.1349-7006.2007.00643.x

Liu, W. G., and Xu, Q. (2019). Upregulation of circHIPK3 Promotes the Progression of Gastric Cancer via Wnt/ $\beta$-Catenin Pathway and Indicates a Poor Prognosis. Eur. Rev. Med. Pharmacol. Sci. 23, 7905-7912. doi:10.26355/ eurrev_201909_19004

Liu, X.-H., Sun, M., Nie, F.-Q., Ge, Y.-B., Zhang, E.-B., Yin, D.-D., et al. (2014). Lnc RNA HOTAIR Functions as a Competing Endogenous RNA to Regulate HER2 Expression by Sponging miR-331-3p in Gastric Cancer. Mol. Cancer 13, 92. doi:10.1186/1476-4598-13-92

Liu, X., Abraham, J. M., Cheng, Y., Wang, Z., Wang, Z., Zhang, G., et al. (2018). Synthetic Circular RNA Functions as a miR-21 Sponge to Suppress Gastric Carcinoma Cell Proliferation. Mol. Ther. - Nucleic Acids 13, 312-321. doi:10.1016/j.omtn.2018.09.010

Liu, X., Lu, Y., Xu, Y., Hou, S., Huang, J., Wang, B., et al. (2019). Exosomal Transfer of miR-501 Confers Doxorubicin Resistance and Tumorigenesis via Targeting of BLID in Gastric Cancer. Cancer Lett. 459, 122-134. doi:10.1016/ j.canlet.2019.05.035

Liu, Y., Lin, W., Dong, Y., Li, X., Lin, Z., Jia, J., et al. (2020). Long Noncoding RNA HCG18 Up-regulates the Expression of WIPF1 and YAP/TAZ by Inhibiting miR-141-3p in Gastric Cancer. Cancer Med. 9, 6752-6765. doi:10.1002/ cam4.3288

Liu, Y. Y., Zhang, L. Y., and Du, W. Z. (2019). Circular RNA Circ-PVT1 Contributes to Paclitaxel Resistance of Gastric Cancer Cells through the Regulation of ZEB1 Expression by Sponging miR-124-3p. Biosci. Rep. 39. doi:10.1042/BSR20193045

Liu, Z., Chen, Z., Fan, R., Jiang, B., Chen, X., Chen, Q., et al. (2017). Over-expressed Long Noncoding RNA HOXA11-AS Promotes Cell Cycle Progression and Metastasis in Gastric Cancer. Mol. Cancer 16, 82. doi:10.1186/s12943-0170651-6

Lu, R., Zhao, G., Yang, Y., Jiang, Z., Cai, J., Zhang, Z., et al. (2019). Long Noncoding RNA HOTAIRM1 Inhibits Cell Progression by Regulating miR-17-5p/PTEN axis in Gastric Cancer. J. Cel Biochem 120, 4952-4965. doi: $10.1002 /$ jcb. 27770

Luan, P. B., Sun, X. M., and Yao, J. (2020). LINC00355 Inhibits Apoptosis and Promotes Proliferation of Gastric Cancer Cells by Regulating Wnt/ $\beta$-Catenin Signaling Pathway. Eur. Rev. Med. Pharmacol. Sci. 24, 8377-8383. doi:10.26355/ eurrev_202008_22634

Ludwig-Galezowska, A. H., Flanagan, L., and Rehm, M. (2011). Apoptosis Repressor with Caspase Recruitment Domain, a Multifunctional Modulator of Cell Death. J. Cel Mol Med 15, 1044-1053. doi:10.1111/j.15824934.2010.01221.x

Luo, G., Zhang, Y., Guo, P., Wang, L., Huang, Y., and Li, K. (2017). Global Patterns and Trends in Stomach Cancer Incidence: Age, Period and Birth Cohort Analysis. Int. J. Cancer 141, 1333-1344. doi:10.1002/ijc.30835

Maeda, K., Chung, Y.-s., Ogawa, Y., Kang, S.-M., Ogawa, M., Sawada, T., et al. (1996). Prognostic Value of Vascular Endothelial Growth Factor Expression in Gastric Carcinoma. Cancer 77, 858-863. doi:10.1002/(sici)10970142(19960301)77:5<858:aid-cncr8>3.0.co;2-a

Mao, Y., Tie, Y., Du, J., and He, J. (2019). LINC00152 Promotes the Proliferation of Gastric Cancer Cells by Regulating B-cell Lymphoma-2. J. Cel Biochem 120, 3747-3756. doi:10.1002/jcb.27655

Markopoulos, G. S., Roupakia, E., Tokamani, M., Chavdoula, E., Hatziapostolou, M., Polytarchou, C., et al. (2017). A Step-by-step microRNA Guide to Cancer
Development and Metastasis. Cel Oncol. 40, 303-339. doi:10.1007/s13402-0170341-9

Meng, L., Chen, Z., Jiang, Z., Huang, T., Hu, J., Luo, P., et al. (2020). MiR-122-5p Suppresses the Proliferation, Migration, and Invasion of Gastric Cancer Cells by Targeting LYN. Acta Biochim. Biophys. Sin (Shanghai) 52, 49-57. doi:10.1093/ abbs/gmz141

Meric-Bernstam, F., Johnson, A. M., Dumbrava, E. E. I., Raghav, K., Balaji, K., Bhatt, M., et al. (2019). Advances in HER2-Targeted Therapy: Novel Agents and Opportunities beyond Breast and Gastric Cancer. Clin. Cancer Res. 25, 2033-2041. doi:10.1158/1078-0432.ccr-18-2275

Miao, Y., Li, Q., Sun, G., Wang, L., Zhang, D., Xu, H., et al. (2020). MiR-5683 Suppresses Glycolysis and Proliferation through Targeting Pyruvate Dehydrogenase Kinase 4 in Gastric Cancer. Cancer Med. 9, 7231-7243. doi:10.1002/cam 4.3344

Montagne, R., Berbon, M., Doublet, L., Debreuck, N., Baranzelli, A., Drobecq, H., et al. (2015). Necrosis- and Apoptosis-Related Met Cleavages Have Divergent Functional Consequences. Cel Death Dis 6, e1769. doi:10.1038/cddis.2015.132

Motoyama, K., Inoue, H., Mimori, K., Tanaka, F., Kojima, K., Uetake, H., et al. (2010). Clinicopathological and Prognostic Significance of PDCD4 and microRNA-21 in Human Gastric Cancer. Int. J. Oncol. 36, 1089-1095. doi:10.3892/ijo_00000590

Ni, J., Tien, A. L., and Fournier, M. J. (1997). Small Nucleolar RNAs Direct Sitespecific Synthesis of Pseudouridine in Ribosomal RNA. Cell 89, 565-573. doi:10.1016/s0092-8674(00)80238-x

Ni, S.-J., Zhao, L.-Q., Wang, X.-F., Wu, Z.-H., Hua, R.-X., Wan, C.-H., et al. (2018). CBX7 Regulates Stem Cell-like Properties of Gastric Cancer Cells via P16 and AKT-NF-Kb-miR-21 Pathways. J. Hematol. Oncol. 11, 17. doi:10.1186/s13045018-0562-z

Ning, T., Zhang, H., Wang, X., Li, S., Zhang, L., Deng, T., et al. (2017). miR-370 Regulates Cell Proliferation and Migration by Targeting EGFR in Gastric Cancer. Oncol. Rep. 38, 384-392. doi:10.3892/or.2017.5660

Ongusaha, P. P., Kim, H.-G., Boswell, S. A., Ridley, A. J., Der, C. J., Dotto, G. P., et al. (2006). RETRACTED: RhoE Is a Pro-survival P53 Target Gene that Inhibits ROCK I-Mediated Apoptosis in Response to Genotoxic Stress. Curr. Biol. 16, 2466-2472. doi:10.1016/j.cub.2006.10.056

Pan, H., Li, T., Jiang, Y., Pan, C., Ding, Y., Huang, Z., et al. (2018). Overexpression of Circular RNA ciRS-7 Abrogates the Tumor Suppressive Effect of miR-7 on Gastric Cancer via PTEN/PI3K/AKT Signaling Pathway. J. Cel. Biochem. 119, 440-446. doi:10.1002/jcb.26201

Park, S.-K., Park, Y. S., Ahn, J. Y., Do, E.-J., Kim, D., Kim, J. E., et al. (2016). MiR 21-5p as a Predictor of Recurrence in Young Gastric Cancer Patients. J. Gastroenterol. Hepatol. 31, 1429-1435. doi:10.1111/jgh.13300

Pei, L.-J., Sun, P.-J., Ma, K., Guo, Y.-Y., Wang, L.-Y., and Liu, F.-D. (2021). LncRNA-SNHG7 Interferes with miR-34a to De-sensitize Gastric Cancer Cells to Cisplatin. Cbm 30, 127-137. doi:10.3233/cbm-201621

Peng, L., Sang, H., Wei, S., Li, Y., Jin, D., Zhu, X., et al. (2020). circCUL2 Regulates Gastric Cancer Malignant Transformation and Cisplatin Resistance by Modulating Autophagy Activation via miR-142-3p/ROCK2. Mol. Cancer 19, 156. doi:10.1186/s12943-020-01270-x

Peng, Y., Guo, J. J., Liu, Y. M., and Wu, X. L. (2014). MicroRNA-34A Inhibits the Growth, Invasion and Metastasis of Gastric Cancer by Targeting PDGFR and MET Expression. Biosci. Rep. 34. doi:10.1042/BSR20140020

Peng, Y., Zhang, X., Lin, H., Deng, S., Huang, Y., Qin, Y., et al. (2018). Inhibition of miR-194 S-uppresses the $\mathrm{Wnt} / \beta$-catenin $\mathrm{S}$-ignalling $\mathrm{P}$-athway in $\mathrm{G}$-astric C-ancer. Oncol. Rep. 40, 3323-3334. doi:10.3892/or.2018.6773

Pereira, A. L., Magalhães, L., Moreira, F. C., Reis-das-Mercês, L., Vidal, A. F., Ribeiro-Dos-Santos, A. M., et al. (2019). Epigenetic Field Cancerization in Gastric Cancer: microRNAs as Promising Biomarkers. J. Cancer 10, 1560-1569. doi:10.7150/jca.27457

Pereira, A. L., Magalhães, L., Pantoja, R. P., Araújo, G., Ribeiro-Dos-Santos, A., and Vidal, A. F. (2020). The Biological Role of Sponge Circular RNAs in Gastric Cancer: Main Players or Coadjuvants? Cancers (Basel) 12. doi:10.3390/ cancers 12071982

Piao, H. Y., Liu, Y., Kang, Y., Wang, Y., Meng, X. Y., Yang, D., et al. (2021). Hypoxia Associated lncRNA HYPAL Promotes Proliferation of Gastric Cancer as ceRNA by Sponging miR-431-5p to Upregulate CDK14 Gastric Cancer.

Pimentel-Nunes, P., Dinis-Ribeiro, M., Ponchon, T., Repici, A., Vieth, M., De Ceglie, A., et al. (2015). Endoscopic Submucosal Dissection: European Society 
of Gastrointestinal Endoscopy (ESGE) Guideline. Endoscopy 47, 829-854. doi:10.1055/s-0034-1392882

Qi, B., Dong, Y., and Qiao, X. L. (2020). Effects of miR-18a on Proliferation and Apoptosis of Gastric Cancer Cells by Regulating RUNX1. Eur. Rev. Med. Pharmacol. Sci. 24, 9957-9964. doi:10.26355/eurrev_202010_23208

Qi, F., Liu, X., Wu, H., Yu, X., Wei, C., Huang, X., et al. (2017). Long Noncoding AGAP2-AS1 Is Activated by SP1 and Promotes Cell Proliferation and Invasion in Gastric Cancer. J. Hematol. Oncol. 10, 48. doi:10.1186/s13045-017-0420-4

Qi, M., Liu, D., and Zhang, S. (2017). MicroRNA-21 Contributes to the Discrimination of Chemoresistance in Metastatic Gastric Cancer. Cbm 18, 451-458. doi: $10.3233 / \mathrm{cbm}-161732$

Qian, Y., Wu, X., Wang, H., Hou, G., Han, X., and Song, W. (2020). MicroRNA4290 Suppresses PDK1-Mediated Glycolysis to Enhance the Sensitivity of Gastric Cancer Cell to Cisplatin. Braz. J. Med. Biol. Res. 53, e9330. doi:10.1590/1414-431X20209330

Qiao, X. L., Zhong, Z. L., Dong, Y., and Gao, F. (2020). LncRNA HMGAlP4 Promotes Cisplatin-Resistance in Gastric Cancer. Eur. Rev. Med. Pharmacol. Sci. 24, 8830-8836. doi:10.26355/eurrev_202009_22822

Quan, J., Dong, D., Lun, Y., Sun, B., Sun, H., Wang, Q., et al. (2020). Circular RNA circHIAT1 Inhibits Proliferation and Epithelial-Mesenchymal Transition of Gastric Cancer Cell Lines through Downregulation of miR-21. J. Biochem. Mol. Toxicol. 34, e22458. doi:10.1002/jbt.22458

Rajagopal, C., and Harikumar, K. B. (2018). The Origin and Functions of Exosomes in Cancer. Front. Oncol. 8, 66. doi:10.3389/fonc.2018.00066

Rong, D., Lu, C., Zhang, B., Fu, K., Zhao, S., Tang, W., et al. (2019). CircPSMC3 Suppresses the Proliferation and Metastasis of Gastric Cancer by Acting as a Competitive Endogenous RNA through Sponging miR-296-5p. Mol. Cancer 18, 25. doi:10.1186/s12943-019-0958-6

Rossi, T., Tedaldi, G., Petracci, E., Abou Khouzam, R., Ranzani, G. N., Morgagni, P., et al. (2019). E-cadherin Downregulation and microRNAs in Sporadic Intestinal-type Gastric Cancer. Int. J. Mol. Sci. 20. doi:10.3390/ijms20184452

Seca, H., Lima, R., Lopes-Rodrigues, V., Guimaraes, J., Gabriela, G., and Vasconcelos, M. (2013). Targeting miR-21 Induces Autophagy and Chemosensitivity of Leukemia Cells. Cdt 14, 1135-1143. doi:10.2174/ 13894501113149990185

Sekiguchi, M., Oda, I., Matsuda, T., and Saito, Y. (2021). Epidemiological Trends and Future Perspectives of Gastric Cancer in Eastern Asia. Digestion 1, 1-7. doi:10.1159/000518483

Shen, J., Niu, W., Zhang, H., Jun, M., and Zhang, H. (2018). Downregulation of MicroRNA-147 Inhibits Cell Proliferation and Increases the Chemosensitivity of Gastric Cancer Cells to 5-Fluorouracil by Directly Targeting PTEN. Oncol. Res. 26, 901-911. doi:10.3727/096504017x15061902533715

Shuai, Y., Ma, Z., Liu, W., Yu, T., Yan, C., Jiang, H., et al. (2020). TEAD4 Modulated LncRNA MNX1-AS1 Contributes to Gastric Cancer Progression Partly through Suppressing BTG2 and Activating BCL2. Mol. Cancer 19, 6. doi:10.1186/ s12943-019-1104-1

Sierzega, M., Kaczor, M., Kolodziejczyk, P., Kulig, J., Sanak, M., and Richter, P. (2017). Evaluation of Serum microRNA Biomarkers for Gastric Cancer Based on Blood and Tissue Pools Profiling: the Importance of miR-21 and miR-331. Br. J. Cancer 117, 266-273. doi:10.1038/bjc.2017.190

Smyth, E. C., Verheij, M., Allum, W., Cunningham, D., Cervantes, A., Arnold, D., et al. (2016). Gastric Cancer: ESMO Clinical Practice Guidelines for Diagnosis, Treatment and Follow-Up. Ann. Oncol. 27, v38-v49. doi:10.1093/annonc/ mdw350

Song, J. H., and Meltzer, S. J. (2012). MicroRNAs in Pathogenesis, Diagnosis, and Treatment of Gastroesophageal Cancers. Gastroenterology 143, 35-47. doi:10.1053/j.gastro.2012.05.003

Song, Y., Wang, R., Li, L. W., Liu, X., Wang, Y. F., Wang, Q. X., et al. (2019). Long Non-coding RNA HOTAIR Mediates the Switching of Histone H3 Lysine 27 Acetylation to Methylation to Promote Epithelial-To-Mesenchymal Transition in Gastric Cancer. Int. J. Oncol. 54, 77-86. doi:10.3892/ijo.2018.4625

Su, Z., Liu, H. L., Qi, B., and Liu, Y. (2020). Effects of Propofol on Proliferation and Apoptosis of Cardia Cancer Cells via MAPK/ERK Signaling Pathway. Eur. Rev. Med. Pharmacol. Sci. 24, 428-433. doi:10.26355/eurrev_202001_19942

Sun, G.-L., Li, Z., Wang, W.-Z., Chen, Z., Zhang, L., Li, Q., et al. (2018). miR-3243p Promotes Gastric Cancer Development by Activating Smad4-Mediated Wnt/beta-Catenin Signaling Pathway. J. Gastroenterol. 53, 725-739. doi:10.1007/s00535-017-1408-0
Sun, G., Li, Z., He, Z., Wang, W., Wang, S., Zhang, X., et al. (2020). Circular RNA MCTP2 Inhibits Cisplatin Resistance in Gastric Cancer by miR-99a-5pMediated Induction of MTMR3 Expression. J. Exp. Clin. Cancer Res. 39, 246. doi:10.1186/s13046-020-01758-w

Sun, K.-K., Shen, X.-J., Yang, D., Gan, M.-Q., Liu, G., Zhang, Y.-F., et al. (2019). MicroRNA-31 Triggers G2/M Cell Cycle Arrest, Enhances the Chemosensitivity and Inhibits Migration and Invasion of Human Gastric Cancer Cells by Downregulating the Expression of Zeste Homolog 2 (ZH2). Arch. Biochem. Biophys. 663, 269-275. doi:10.1016/j.abb.2019.01.023

Takei, Y., Hara, T., Suzuki, A., Mihara, K., and Yanagihara, K. (2020). Long Noncoding RNA Hotair Promotes Epithelial-Mesenchymal Transition and Is a Suitable Target to Inhibit Peritoneal Dissemination in Human Scirrhous Gastric Cancers. Pathobiology 87, 277-290. doi:10.1159/000508350

Tao, S., Gu, J., Wang, Q., and Zheng, L. (2021). Translational Control of Bcl-2 Promotes Apoptosis of Gastric Carcinoma Cells. BMC Cancer 21, 12. doi:10.1186/s12885-020-07711-6

Tao, Y., Wan, X., Fan, Q., Wang, Y., Sun, H., Ma, L., et al. (2020). Long Non-coding RNA OIP5-AS1 Promotes the Growth of Gastric Cancer through the miR-3673p/HMGA2 axis. Dig. Liver Dis. 52, 773-779. doi:10.1016/j.dld.2019.11.017

Taylor, M. A., Das, B. C., and Ray, S. K. (2018). Targeting Autophagy for Combating Chemoresistance and Radioresistance in Glioblastoma. Apoptosis 23, 563-575. doi:10.1007/s10495-018-1480-9

Thrift, A. P., and El-Serag, H. B. (2020). Burden of Gastric Cancer. Clin. Gastroenterol. Hepatol. 18, 534-542. doi:10.1016/j.cgh.2019.07.045

Tian, R., Jiang, H., Shao, L., Yu, Y., Guo, Q., Cao, B., et al. (2020). miR193b Promotes Apoptosis of Gastric Cancer Cells via Directly Mediating the Akt Pathway. Biomed. Res. Int. 2020, 2863236. doi:10.1155/2020/2863236

Tian, Y., Ma, R., Sun, Y., Liu, H., Zhang, H., Sun, Y., et al. (2020). SP1activated Long Noncoding RNA lncRNA GCMA Functions as a Competing Endogenous RNA to Promote Tumor Metastasis by Sponging miR-124 and miR-34a in Gastric Cancer. Oncogene 39, 4854-4868. doi:10.1038/s41388-020-1330-4

Tokumaru, Y., Tajirika, T., Sugito, N., Kuranaga, Y., Shinohara, H., Tsujino, T., et al. (2019). Synthetic miR-143 Inhibits Growth of HER2-Positive Gastric Cancer Cells by Suppressing KRAS Networks Including DDX6 RNA Helicase. Int. J. Mol. Sci. 20. doi:10.3390/ijms20071697

Vanas, V., Haigl, B., Stockhammer, V., and Sutterlüty-Fall, H. (2016). MicroRNA21 Increases Proliferation and Cisplatin Sensitivity of Osteosarcoma-Derived Cells. PLoS One 11, e0161023. doi:10.1371/journal.pone.0161023

Viallard, C., and Larrivée, B. (2017). Tumor Angiogenesis and Vascular Normalization: Alternative Therapeutic Targets. Angiogenesis 20, 409-426. doi:10.1007/s10456-017-9562-9

Volinia, S., Calin, G. A., Liu, C.-G., Ambs, S., Cimmino, A., Petrocca, F., et al. (2006). A microRNA Expression Signature of Human Solid Tumors Defines Cancer Gene Targets. Pnas 103, 2257-2261. doi:10.1073/pnas.0510565103

Voss, V., Senft, C., Lang, V., Ronellenfitsch, M. W., Steinbach, J. P., Seifert, V., et al. (2010). The Pan-Bcl-2 Inhibitor (-)-Gossypol Triggers Autophagic Cell Death in Malignant Glioma. Mol. Cancer Res. 8, 1002-1016. doi:10.1158/15417786.mcr-09-0562

Wang, H., Qin, R., Guan, A., Yao, Y., Huang, Y., Jia, H., et al. (2018). HOTAIR Enhanced Paclitaxel and Doxorubicin Resistance in Gastric Cancer Cells Partly through Inhibiting miR-217 Expression. J. Cel Biochem 119, 7226-7234. doi:10.1002/jcb.26901

Wang, J., Feng, W., Dong, Y., Mao, X., Guo, F., and Luo, F. (2018). MicroRNA-495 $\mathrm{R}$-egulates $\mathrm{H}$-uman $\mathrm{G}$-astric $\mathrm{C}$-ancer $\mathrm{C}$-ell A-poptosis and $\mathrm{M}$-igration through Akt and mTOR S-ignaling. Oncol. Rep. 40, 3654-3662. doi:10.3892/ or.2018.6722

Wang, J., Yu, Z., Wang, J., Shen, Y., Qiu, J., and Zhuang, Z. (2020). LncRNA NUTM2A-AS1 Positively Modulates TET1 and HIF-1A to Enhance Gastric Cancer Tumorigenesis and Drug Resistance by Sponging miR-376a. Cancer Med. 9, 9499-9510. doi:10.1002/cam4.3544

Wang, L., Zhang, H., Zheng, J., Wei, X., Du, J., Lu, H., et al. (2018). Dual Silencing of EGFR and HER2 Enhances the Sensitivity of Gastric Cancer Cells to Gefitinib. Mol. Carcinogenesis 57, 1008-1016. doi:10.1002/mc.22821

Wang, M., Qiu, R., Yu, S., Xu, X., Li, G., Gu, R., et al. (2019). Paclitaxelresistant Gastric Cancer MGC803 Cells Promote Epithelialtomesenchymal Transition and Chemoresistance in Paclitaxelsensitive Cells via Exosomal Delivery of miR1555p. Int. J. Oncol. 54, 326-338. 
Wang, P., Guan, Q., Zhou, D., Yu, Z., Song, Y., and Qiu, W. (2018). miR-21 Inhibitors Modulate Biological Functions of Gastric Cancer Cells via PTEN/ PI3K/mTOR Pathway. DNA Cel Biol. 37, 38-45. doi:10.1089/dna.2017.3922

Wang, S., Ping, M., Song, B., Guo, Y., Li, Y., and Jia, J. (2020). Exosomal CircPRRX1 Enhances Doxorubicin Resistance in Gastric Cancer by Regulating MiR-30645p/PTPN14 Signaling. Yonsei Med. J. 61, 750-761. doi:10.3349/ ymj.2020.61.9.750

Wang, W., Zhao, J., Wang, H., Sun, Y., Peng, Z., Zhou, G., et al. (2010). Programmed Cell Death 4 (PDCD4) Mediates the Sensitivity of Gastric Cancer Cells to TRAIL-Induced Apoptosis by Down-Regulation of FLIP Expression. Exp. Cel Res. 316, 2456-2464. doi:10.1016/j.yexcr.2010.05.027

Wang, X.-y., Zhou, Y.-c., Wang, Y., Liu, Y.-y., Wang, Y.-X., Chen, D.-d., et al. (2020). miR-149 Contributes to Resistance of 5-FU in Gastric Cancer via Targeting TREM2 and Regulating $\beta$-catenin Pathway. Biochem. Biophysical Res. Commun. 532, 329-335. doi:10.1016/j.bbrc.2020.05.135

Wang, X., Wang, C., Zhang, X., Hua, R., Gan, L., Huang, M., et al. (2016). Bmi-1 Regulates Stem Cell-like Properties of Gastric Cancer Cells via Modulating miRNAs. J. Hematol. Oncol. 9, 90. doi:10.1186/s13045-016-0323-9

Wang, X., Zhang, H., Bai, M., Ning, T., Ge, S., Deng, T., et al. (2018). Exosomes Serve as Nanoparticles to Deliver Anti-miR-214 to Reverse Chemoresistance to Cisplatin in Gastric Cancer. Mol. Ther. 26, 774-783. doi:10.1016/ j.ymthe.2018.01.001

Wang, Y., Zhang, H., Ge, S., Fan, Q., Zhou, L., Li, H., et al. (2018). Effects of miR138-5p and miR-204-5p on the M-igration and P-roliferation of G-astric C-ancer C-ells by T-argeting EGFR. Oncol. Rep. 39, 2624-2634. doi:10.3892/ or.2018.6389

Wang, Z.-Q., Cai, Q., Hu, L., He, C.-Y., Li, J.-F., Quan, Z.-W., et al. (2017). Long Noncoding RNA UCA1 Induced by SP1 Promotes Cell Proliferation via Recruiting EZH2 and Activating AKT Pathway in Gastric Cancer. Cel Death Dis 8, e2839. doi:10.1038/cddis.2017.143

Wei, J., Xu, H., Wei, W., Wang, Z., Zhang, Q., De, W., et al. (2020). circHIPK3 Promotes Cell Proliferation and Migration of Gastric Cancer by Sponging miR107 and Regulating BDNF Expression. Ott 13, 1613-1624. doi:10.2147/ ott.s226300

Wei, L., Sun, J., Zhang, N., Zheng, Y., Wang, X., Lv, L., et al. (2020). Noncoding RNAs in Gastric Cancer: Implications for Drug Resistance. Mol. Cancer 19, 62. doi:10.1186/s12943-020-01185-7

Wei, L., Wang, X., Lv, L., Liu, J., Xing, H., Song, Y., et al. (2019). The Emerging Role of microRNAs and Long Noncoding RNAs in Drug Resistance of Hepatocellular Carcinoma. Mol. Cancer 18, 147. doi:10.1186/s12943-0191086-z

Wei, Z., Chen, L., Meng, L., Han, W., Huang, L., and Xu, A. (2020). LncRNA HOTAIR Promotes the Growth and Metastasis of Gastric Cancer by Sponging miR-1277-5p and Upregulating COL5A1. Gastric Cancer 23, 1018-1032. doi:10.1007/s10120-020-01091-3

Welch, C., Chen, Y., and Stallings, R. L. (2007). MicroRNA-34a Functions as a Potential Tumor Suppressor by Inducing Apoptosis in Neuroblastoma Cells. Oncogene 26, 5017-5022. doi:10.1038/sj.onc.1210293

Wen, J., Liao, J., Liang, J., Chen, X.-p., Zhang, B., and Chu, L. (2020). Circular RNA HIPK3: A Key Circular RNA in a Variety of Human Cancers. Front. Oncol. 10, 773. doi:10.3389/fonc.2020.00773

Wu, J., Li, G., Wang, Z., Yao, Y., Chen, R., Pu, X., et al. (2015). Circulating MicroRNA-21 Is a Potential Diagnostic Biomarker in Gastric Cancer. Dis. Markers 2015, 435656. doi:10.1155/2015/435656

Wu, Q., Xiang, S., Ma, J., Hui, P., Wang, T., Meng, W., et al. (2018). Long Noncoding RNA CASC 15 Regulates Gastric Cancer Cell Proliferation, Migration and Epithelial Mesenchymal Transition by Targeting CDKN 1A and ZEB 1. Mol. Oncol. 12, 799-813. doi:10.1002/1878-0261.12187

Wu, Y.-Y., Tsai, H. F., Lin, W. C., Chou, A. H., Chen, H. T., Yang, J. C., et al. (2004). Helicobacter Pylorienhances Tumor Necrosis Factor-Related ApoptosisInducing Ligand-Mediated Apoptosis in Human Gastric Epithelial Cells. Wjg 10, 2334-2339. doi:10.3748/wjg.v10.i16.2334

Wu, Y., Zhang, J., Zheng, Y., Ma, C., Liu, X.-E., and Sun, X. (2018). miR-216a-3p Inhibits the Proliferation, Migration, and Invasion of Human Gastric Cancer Cells via Targeting RUNX1 and Activating the NF-Kb Signaling Pathway. Oncol. Res. 26, 157-171. doi:10.3727/096504017x15031557924150

Xi, Z., Si, J., and Nan, J. (2019). LncRNA MALAT1 Potentiates Autophagyassociated C-isplatin R-esistance by R-egulating the microRNA-30b/ autophagy-related G-ene 5 axis in G-astric C-ancer. Int. J. Oncol. 54, 239-248. doi:10.3892/ijo.2018.4609

Xiao, J., Lai, H., Wei, S. H., Ye, Z. S., Gong, F. S., and Chen, L. C. (2019). Lnc RNA HOTAIR Promotes Gastric Cancer Proliferation and Metastasis via Targeting miR-126 to Active CXCR 4 and RhoA Signaling Pathway. Cancer Med. 8, 6768-6779. doi:10.1002/cam4.1302

Xie, M., Dart, D. A., Guo, T., Xing, X.-F., Cheng, X.-J., Du, H., et al. (2018). MicroRNA-1 Acts as a Tumor Suppressor microRNA by Inhibiting Angiogenesis-Related Growth Factors in Human Gastric Cancer. Gastric Cancer 21, 41-54. doi:10.1007/s10120-017-0721-x

Xie, M., Yu, T., Jing, X., Ma, L., Fan, Y., Yang, F., et al. (2020). Exosomal circSHKBP1 Promotes Gastric Cancer Progression via Regulating the miR582-3p/HUR/VEGF axis and Suppressing HSP90 Degradation. Mol. Cancer 19, 112. doi:10.1186/s12943-020-01208-3

Xie, Y., Yuan, X., Zhou, W., Kosiba, A. A., Shi, H., Gu, J., et al. (2020). The Circular RNA HIPK3 (circHIPK3) and its Regulation in Cancer Progression: Review. Life Sci. 254, 117252. doi:10.1016/j.lfs.2019.117252

Xu, T.-P., Ma, P., Wang, W.-Y., Shuai, Y., Wang, Y.-F., Yu, T., et al. (2019). KLF5 and MYC Modulated LINC00346 Contributes to Gastric Cancer Progression through Acting as a Competing Endogeous RNA and Indicates Poor Outcome. Cell Death Differ 26, 2179-2193. doi:10.1038/s41418-018-0236-y

Xu, T.-p., Wang, W.-y., Ma, P., Shuai, Y., Zhao, K., Wang, Y.-f., et al. (2018). Upregulation of the Long Noncoding RNA FOXD2-AS1 Promotes Carcinogenesis by Epigenetically Silencing EphB3 through EZH2 and LSD1, and Predicts Poor Prognosis in Gastric Cancer. Oncogene 37, 5020-5036. doi:10.1038/s41388-018-0308-y

Xu, Z., Chen, H., Yang, B., Liu, X., Zhou, X., and Kong, H. (2019). The Association of HOTAIR with the Diagnosis and Prognosis of Gastric Cancer and its Effect on the Proliferation of Gastric Cancer Cells. Can. J. Gastroenterol. Hepatol. 2019, 3076345. doi:10.1155/2019/3076345

Yan, R., Li, K., Yuan, D. W., Wang, H. N., Zhang, Y., Dang, C. X., et al. (2018). Downregulation of microRNA-4295 Enhances Cisplatin-Induced Gastric Cancer Cell Apoptosis through the EGFR/PI3K/Akt Signaling Pathway by Targeting LRIG1. Int. J. Oncol. 53, 2566-2578. doi:10.3892/ijo.2018.4595

Yang, D., Hu, Z., Zhang, Y., Zhang, X., Xu, J., Fu, H., et al. (2021). CircHIPK3 Promotes the Tumorigenesis and Development of Gastric Cancer through miR-637/AKT1 Pathway. Front. Oncol. 11, 637761. doi:10.3389/ fonc.2021.637761

Yang, H., Zhang, H., Ge, S., Ning, T., Bai, M., Li, J., et al. (2018). Exosome-Derived miR-130a Activates Angiogenesis in Gastric Cancer by Targeting C-MYB in Vascular Endothelial Cells. Mol. Ther. 26, 2466-2475. doi:10.1016/ j.ymthe.2018.07.023

Yang, S.-m., Huang, C., Li, X.-f., Yu, M.-Z., He, Y., and Li, J. (2013). miR-21 Confers Cisplatin Resistance in Gastric Cancer Cells by Regulating PTEN. Toxicology 306, 162-168. doi:10.1016/j.tox.2013.02.014

Yang, X.-Z., Cheng, T.-T., He, Q.-J., Lei, Z.-Y., Chi, J., Tang, Z., et al. (2018). LINC01133 as ceRNA Inhibits Gastric Cancer Progression by Sponging miR106a-3p to Regulate APC Expression and the Wnt/ $\beta$-Catenin Pathway. Mol. Cancer 17, 126. doi:10.1186/s12943-018-0874-1

Yang, Y. L., Liu, P., Li, D., Yang, Q., Li, B., and Jiang, X. J. (2020). Stat-3 Signaling Promotes Cell Proliferation and Metastasis of Gastric Cancer through PDCD4 Downregulation. Kaohsiung J. Med. Sci. 36, 244-249. doi:10.1002/kjm2.12159

Yang, Z., Fang, S., Di, Y., Ying, W., Tan, Y., and Gu, W. (2015). Modulation of NFkB/miR-21/PTEN Pathway Sensitizes Non-small Cell Lung Cancer to Cisplatin. PLoS One 10, e0121547. doi:10.1371/journal.pone.0121547

YiRen, H., YingCong, Y., Sunwu, Y., Keqin, L., Xiaochun, T., Senrui, C., et al. (2017). Long Noncoding RNA MALAT1 Regulates Autophagy Associated Chemoresistance via miR-23b-3p Sequestration in Gastric Cancer. Mol. Cancer 16, 174. doi:10.1186/s12943-017-0743-3

Yu, Y., Yu, X., Liu, H., Song, Q., and Yang, Y. (2018). miR-494 I-nhibits $\mathrm{C}$-ancer-initiating $\mathrm{C}$-ell $\mathrm{P}$-henotypes and R-everses $\mathrm{R}$-esistance to L-apatinib by D-ownregulating FGFR2 in HER2-positive G-astric C-ancer. Int. J. Mol. Med. 42, 998-1007. doi:10.3892/ijmm.2018.3680

Yuan, X. H., Li, J., Cao, Y., Jie, Z. G., and Zeng, Y. F. (2020). Long Non-coding RNA AFAP1-AS1 Promotes Proliferation and Migration of Gastric Cancer by Downregulating KLF2. Eur. Rev. Med. Pharmacol. Sci. 24, 673-680. doi:10.26355/eurrev_202001_20044 
Zhang, B. G., Li, J. F., Yu, B. Q., Zhu, Z. G., Liu, B. Y., and Yan, M. (2012). microRNA-21 Promotes Tumor Proliferation and Invasion in Gastric Cancer by Targeting PTEN. Oncol. Rep. 27, 1019-1026. doi:10.3892/or.2012.1645

Zhang, C., Zhang, C.-D., Liang, Y., Wu, K.-Z., Pei, J.-P., and Dai, D.-Q. (2020). The Comprehensive Upstream Transcription and Downstream Targeting Regulation Network of miRNAs Reveal Potential Diagnostic Roles in Gastric Cancer. Life Sci. 253, 117741. doi:10.1016/ j.lfs.2020.117741

Zhang, F., Li, Y., Xu, W., He, L., Tan, Y., and Xu, H. (2019). Long Non-coding RNA ZFAS1 Regulates the Malignant Progression of Gastric Cancer via the microRNA-200b-3p/Wnt1 axis. Biosci. Biotechnol. Biochem. 83, 1289-1299. doi:10.1080/09168451.2019.1606697

Zhang, G., Li, S., Lu, J., Ge, Y., Wang, Q., Ma, G., et al. (2018). LncRNA MT1JP Functions as a ceRNA in Regulating FBXW7 through Competitively Binding to miR-92a-3p in Gastric Cancer. Mol. Cancer 17, 87. doi:10.1186/s12943-0180829-6

Zhang, G., Xu, Y., Wang, S., Gong, Z., Zou, C., Zhang, H., et al. (2019). LncRNA SNHG17 Promotes Gastric Cancer Progression by Epigenetically Silencing of P15 and P57. J. Cel Physiol 234, 5163-5174. doi:10.1002/jcp.27320

Zhang, H., Deng, T., Liu, R., Ning, T., Yang, H., Liu, D., et al. (2020). CAF Secreted miR-522 Suppresses Ferroptosis and Promotes Acquired ChemoResistance in Gastric Cancer. Mol. Cancer 19, 43. doi:10.1186/s12943-02001168-8

Zhang, H., Duan, J., Qu, Y., Deng, T., Liu, R., Zhang, L., et al. (2016). Onco-miR-24 Regulates Cell Growth and Apoptosis by Targeting BCL2L11 in Gastric Cancer. Protein Cell 7, 141-151. doi:10.1007/s13238-015-0234-5

Zhang, J.-X., Xu, Y., Gao, Y., Chen, C., Zheng, Z.-S., Yun, M., et al. (2017). Decreased Expression of miR-939 Contributes to Chemoresistance and Metastasis of Gastric Cancer via Dysregulation of SLC34A2 and Raf/MEK/ ERK Pathway. Mol. Cancer 16, 18. doi:10.1186/s12943-017-0586-y

Zhang, J., Liu, H., Hou, L., Wang, G., Zhang, R., Huang, Y., et al. (2017). Circular RNA_LARP4 Inhibits Cell Proliferation and Invasion of Gastric Cancer by Sponging miR-424-5p and Regulating LATS1 Expression. Mol. Cancer 16, 151. doi:10.1186/s12943-017-0719-3

Zhang, J., Qiu, W.-Q., Zhu, H., Liu, H., Sun, J.-H., Chen, Y., et al. (2020). HOTAIR Contributes to the Carcinogenesis of Gastric Cancer via Modulating Cellular and Exosomal miRNAs Level. Cel Death Dis 11, 780. doi:10.1038/s41419-02002946-4

Zhang, M., Wang, S., Yi, A., and Qiao, Y. (2020). microRNA-665 Is Downregulated in Gastric Cancer and Inhibits Proliferation, Invasion, and EMT by Targeting PPP2R2A. Cel Biochem Funct 38, 409-418. doi:10.1002/ cbf. 3485

Zhang, X., Li, M., Chen, S., Hu, J., Guo, Q., Liu, R., et al. (2018). Endoscopic Screening in Asian Countries Is Associated with Reduced Gastric Cancer Mortality: A Meta-Analysis and Systematic Review. Gastroenterology 155, 347-354. doi:10.1053/j.gastro.2018.04.026

Zhang, X., Wang, S., Wang, H., Cao, J., Huang, X., Chen, Z., et al. (2019). Circular RNA circNRIP1 Acts as a microRNA-149-5p Sponge to Promote Gastric Cancer Progression via the AKT1/mTOR Pathway. Mol. Cancer 18, 20. doi:10.1186/s12943-018-0935-5

Zhang, Y.-F., Li, C.-S., Zhou, Y., and Lu, X.-H. (2020). Propofol facilitates cisplatin sensitivity via lncRNA MALAT1/miR-30e/ATG5 axis through suppressing autophagy in gastric cancer. Life Sci. 244, 117280. doi:10.1016/j.lfs.2020.117280

Zhang, Y., Bai, J., Si, W., Yuan, S., Li, Y., and Chen, X. (2020). SLC39A7, Regulated by miR-139-5p, Induces Cell Proliferation, Migration and Inhibits Apoptosis in Gastric Cancer via Akt/mTOR Signaling Pathway. Biosci. Rep. 40. doi:10.1042/ BSR20200041

Zhang, Y., Xu, W., Ni, P., Li, A., Zhou, J., and Xu, S. (2016). MiR-99a and MiR-491 Regulate Cisplatin Resistance in Human Gastric Cancer Cells by Targeting CAPNS1. Int. J. Biol. Sci. 12, 1437-1447. doi:10.7150/ijbs.16529

Zhang, Y., Yuan, Y., Zhang, Y., Cheng, L., Zhou, X., and Chen, K. (2020). SNHG7 Accelerates Cell Migration and Invasion through Regulating miR-34a-SnailEMT axis in Gastric Cancer. Cell Cycle 19, 142-152. doi:10.1080/ 15384101.2019.1699753

Zhang, Z., Fan, B., Liu, F., Song, N., Peng, Y., Ma, W., et al. (2019). HOX Transcript Antisense RNA Is Elevated in Gastric Carcinogenesis and

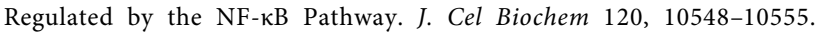
doi: $10.1002 /$ jcb. 28340

Zhang, Z., Kong, Y., Yang, W., Ma, F., Zhang, Y., Ji, S., et al. (2016). Upregulation of microRNA-34a Enhances the DDP Sensitivity of Gastric Cancer Cells by Modulating Proliferation and Apoptosis via Targeting MET. Oncol. Rep. 36, 2391-2397. doi:10.3892/or.2016.5016

Zhao, D. L., and Wu, Q. L. (2019). Effect of Inhibition to Yes-Related ProteinsMediated Wnt/ $\beta$-Catenin Signaling Pathway through miR-195-5p on Apoptosis of Gastric Cancer Cells. Eur. Rev. Med. Pharmacol. Sci. 23, 6486-6496. doi:10.26355/eurrev_201908_18532

Zhao, J., Du, P., Cui, P., Qin, Y., Hu, C. e., Wu, J., et al. (2018). LncRNA PVT1 Promotes Angiogenesis via Activating the STAT3/VEGFA axis in Gastric Cancer. Oncogene 37, 4094-4109. doi:10.1038/s41388-018-0250-Z

Zhao, J., Nie, Y., Wang, H., and Lin, Y. (2016). MiR-181a Suppresses Autophagy and Sensitizes Gastric Cancer Cells to Cisplatin. Gene 576, 828-833. doi:10.1016/j.gene.2015.11.013

Zhao, J., Xiao, A., Liu, C., Ye, C., Yin, K., Lu, M., et al. (2020). The HIF-1A/ miR-17-5p/PDCD4 axis Contributes to the Tumor Growth and Metastasis of Gastric Cancer. Sig Transduct Target. Ther. 5, 46. doi:10.1038/s41392020-0132-z

Zhao, Q., Li, Y., Tan, B.-B., Fan, L.-Q., Yang, P.-G., and Tian, Y. (2015). HIF$1 \alpha$ Induces Multidrug Resistance in Gastric Cancer Cells by Inducing MiR27a. PLoS One 10, e0132746. doi:10.1371/journal.pone.0132746

Zhen, Y., Guanghui, L., and Xiefu, Z. (2014). Knockdown of EGFR Inhibits Growth and Invasion of Gastric Cancer Cells. Cancer Gene Ther. 21, 491-497. doi:10.1038/cgt.2014.55

Zheng, P., Chen, L., Yuan, X., Luo, Q., Liu, Y., Xie, G., et al. (2017). Exosomal Transfer of Tumor-Associated Macrophage-Derived miR-21 Confers Cisplatin Resistance in Gastric Cancer Cells. J. Exp. Clin. Cancer Res. 36, 53. doi:10.1186/ s13046-017-0528-y

Zheng, X., Dong, L., Wang, K., Zou, H., Zhao, S., Wang, Y., et al. (2019). MiR-21 Participates in the PD-1/pd-L1 Pathway-Mediated Imbalance of Th17/Treg Cells in Patients after Gastric Cancer Resection. Ann. Surg. Oncol. 26, 884-893. doi:10.1245/s10434-018-07117-6

Zheng, X., Mao, X., Xu, K., Lü, L., Peng, X., Wang, M., et al. (2015). Massive Endoscopic Screening for Esophageal and Gastric Cancers in a High-Risk Area of China. PLoS One 10, e0145097. doi:10.1371/journal.pone.0145097

Zheng, Y., Cui, L., Sun, W., Zhou, H., Yuan, X., Huo, M., et al. (2011). MicroRNA21 Is a New Marker of Circulating Tumor Cells in Gastric Cancer Patients. Cancer Biomark 10, 71-77. doi:10.3233/CBM-2011-0231

Zhou, G. R., Huang, D. P., Sun, Z. F., and Zhang, X. F. (2020). Long Noncoding RNA BCAR4 Accelerates Cell Proliferation and Suppresses Cell Apoptosis in Gastric Cancer via Regulating MAPK/ERK Signaling. Eur. Rev. Med. Pharmacol. Sci. 24, 3657-3664. doi:10.26355/ eurrev_202004_20828

Zhou, J., and Chen, Q. (2019). Poor Expression of microRNA-135b Results in the Inhibition of Cisplatin Resistance and Proliferation and Induces the Apoptosis of Gastric Cancer Cells through MST1-mediated MAPK Signaling Pathway. FASEB j. 33, 3420-3436. doi:10.1096/fj.201800618rrr

Zhou, M., Zhang, X.-Y., and Yu, X. (2017). Overexpression of the Long Noncoding RNA SPRY4-IT1 Promotes Tumor Cell Proliferation and Invasion by Activating EZH2 in Hepatocellular Carcinoma. Biomed. Pharmacother. 85, 348-354. doi:10.1016/j.biopha.2016.11.035

Zhou, X., Men, X., Zhao, R., Han, J., Fan, Z., Wang, Y., et al. (2018). miR-200c Inhibits TGF- $\beta$-Induced-EMT to Restore Trastuzumab Sensitivity by Targeting ZEB1 and ZEB2 in Gastric Cancer. Cancer Gene Ther. 25, 68-76. doi:10.1038/ s41417-017-0005-y

Zhou, Y., Huang, T., Siu, H. L., Wong, C. C., Dong, Y., Wu, F., et al. (2017). IGF2BP3 Functions as a Potential Oncogene and Is a Crucial Target of miR-34a in Gastric Carcinogenesis. Mol. Cancer 16, 77. doi:10.1186/ s12943-017-0647-2

Zhu, L., Lin, X., Zhi, L., Fang, Y., Lin, K., Li, K., et al. (2020). Mesenchymal Stem Cells Promote Human Melanocytes Proliferation and Resistance to Apoptosis through PTEN Pathway in Vitiligo. Stem Cel Res Ther 11, 26. doi:10.1186/ s13287-019-1543-Z

Zhu, L., Zhu, Y., Han, S., Chen, M., Song, P., Dai, D., et al. (2019). Impaired Autophagic Degradation of IncRNA ARHGAP5-AS1 Promotes 
Chemoresistance in Gastric Cancer. Cel Death Dis 10, 383. doi:10.1038/s41419019-1585-2

Zhu, Q. L., Li, Z., Lv, C. M., and Wang, W. (2019). MiR-187 Influences CisplatinResistance of Gastric Cancer Cells through Regulating the TGF- $\beta /$ Smad Signaling Pathway. Eur. Rev. Med. Pharmacol. Sci. 23, 9907-9914. doi:10.26355/eurrev_201911_19556

Zhu, Y., Tchkonia, T., Fuhrmann-Stroissnigg, H., Dai, H. M., Ling, Y. Y., Stout, M. B., et al. (2016). Identification of a Novel Senolytic Agent, Navitoclax, Targeting the Bcl-

2 Family of Anti-apoptotic Factors. Aging Cell 15, 428-435. doi:10.1111/acel.12445

Conflict of Interest: The authors declare that the research was conducted in the absence of any commercial or financial relationships that could be construed as a potential conflict of interest.
Publisher's Note: All claims expressed in this article are solely those of the authors and do not necessarily represent those of their affiliated organizations, or those of the publisher, the editors and the reviewers. Any product that may be evaluated in this article, or claim that may be made by its manufacturer, is not guaranteed or endorsed by the publisher.

Copyright $\odot 2021$ Yue, Lin, Qiu, Yang and Wang. This is an open-access article distributed under the terms of the Creative Commons Attribution License (CC BY).

The use, distribution or reproduction in other forums is permitted, provided the original author(s) and the copyright owner(s) are credited and that the original publication in this journal is cited, in accordance with accepted academic practice. No use, distribution or reproduction is permitted which does not comply with these terms. 